\title{
RESEARCH
}

Open Access

\section{CD4+ effector T cells accelerate Alzheimer's disease in mice}

\author{
Jatin Machhi ${ }^{1 *}$, Pravin Yeapuri ${ }^{1}$, Yaman Lu' ${ }^{1}$ Emma Foster ${ }^{2}$, Rupesh Chikhale ${ }^{3}$, Jonathan Herskovitz ${ }^{4}$, \\ Krista L. Namminga ${ }^{1}$, Katherine E. Olson ${ }^{1}$, Mai Mohamed Abdelmoaty ${ }^{5,6}$, Ju Gao ${ }^{1}$, Rolen M. Quadros ${ }^{1,7}$, \\ Tomomi Kiyota ${ }^{8}$, Liang Jingjing ${ }^{1}$, Bhavesh D. Kevadiya ${ }^{1}$, Xinglong Wang ${ }^{1}$, Yutong Liu ${ }^{1,9}$, Larisa Y. Poluektova ${ }^{1}$, \\ Channabasavaiah B. Gurumurthy ${ }^{1,7}$, R. Lee Mosley ${ }^{1}$ and Howard E. Gendelman ${ }^{1,5^{*}}$ (1)
}

\begin{abstract}
Background: Alzheimer's disease (AD) is a progressive neurodegenerative disorder characterized by pathological deposition of misfolded self-protein amyloid beta (A $\beta$ ) which in kind facilitates tau aggregation and neurodegeneration. Neuroinflammation is accepted as a key disease driver caused by innate microglia activation. Recently, adaptive immune alterations have been uncovered that begin early and persist throughout the disease. How these occur and whether they can be harnessed to halt disease progress is unclear. We propose that self-antigens would induct autoreactive effector T cells (Teffs) that drive pro-inflammatory and neurodestructive immunity leading to cognitive impairments. Here, we investigated the role of effector immunity and how it could affect cellular-level disease pathobiology in an AD animal model.
\end{abstract}

Methods: In this report, we developed and characterized cloned lines of amyloid beta (A $\beta$ ) reactive type $1 \mathrm{~T}$ helper (Th1) and type 17 Th (Th17) cells to study their role in AD pathogenesis. The cellular phenotype and antigen-specificity of A $\mathrm{B}$-specific Th1 and Th17 clones were confirmed using flow cytometry, immunoblot staining and A $\mathrm{T}$ cell epitope loaded haplotype-matched major histocompatibility complex II IA ${ }^{\mathrm{b}}$ (MHCII-IA ${ }^{\mathrm{b}}$-KLVFFAEDVGSNKGA) tetramer binding. A $\beta$-Th1 and A $\beta$-Th 17 clones were adoptively transferred into APP/PS1 double-transgenic mice expressing chimeric mouse/human amyloid precursor protein and mutant human presenilin 1, and the mice were assessed for memory impairments. Finally, blood, spleen, lymph nodes and brain were harvested for immunological, biochemical, and histological analyses.

Results: The propagated A $\beta$-Th1 and A $\beta$-Th17 clones were confirmed stable and long-lived. Treatment of APP/PS1 mice with $A \beta$ reactive Teffs accelerated memory impairment and systemic inflammation, increased amyloid burden, elevated microglia activation, and exacerbated neuroinflammation. Both Th1 and Th17 Aß-reactive Teffs progressed AD pathology by downregulating anti-inflammatory and immunosuppressive regulatory $T$ cells (Tregs) as recorded in the periphery and within the central nervous system.

Conclusions: These results underscore an important pathological role for CD4+ Teffs in AD progression. We posit that aberrant disease-associated effector $T$ cell immune responses can be controlled. One solution is by A $\beta$ reactive Tregs.

\footnotetext{
*Correspondence: jatin.machhi@unmc.edu; hegendel@unmc.edu

${ }^{1}$ Department of Pharmacology and Experimental Neuroscience,

University of Nebraska Medical Center, Omaha, NE 68198, USA

Full list of author information is available at the end of the article
} permits use, sharing, adaptation, distribution and reproduction in any medium or format, as long as you give appropriate credit to the original author(s) and the source, provide a link to the Creative Commons licence, and indicate if changes were made. The images or other third party material in this article are included in the article's Creative Commons licence, unless indicated otherwise in a credit line to the material. If material is not included in the article's Creative Commons licence and your intended use is not permitted by statutory regulation or exceeds the permitted use, you will need to obtain permission directly from the copyright holder. To view a copy of this licence, visit http://creativecommons.org/licenses/by/4.0/. The Creative Commons Public Domain Dedication waiver (http://creativeco mmons.org/publicdomain/zero/1.0/) applies to the data made available in this article, unless otherwise stated in a credit line to the data. 
Keywords: Alzheimer's disease (AD), Amyloid beta (Aß), T cell, EffectorT cell (Teff), Regulatory T cell (Treg), APP/PS1 transgenic mice

\section{Graphical Abstract}

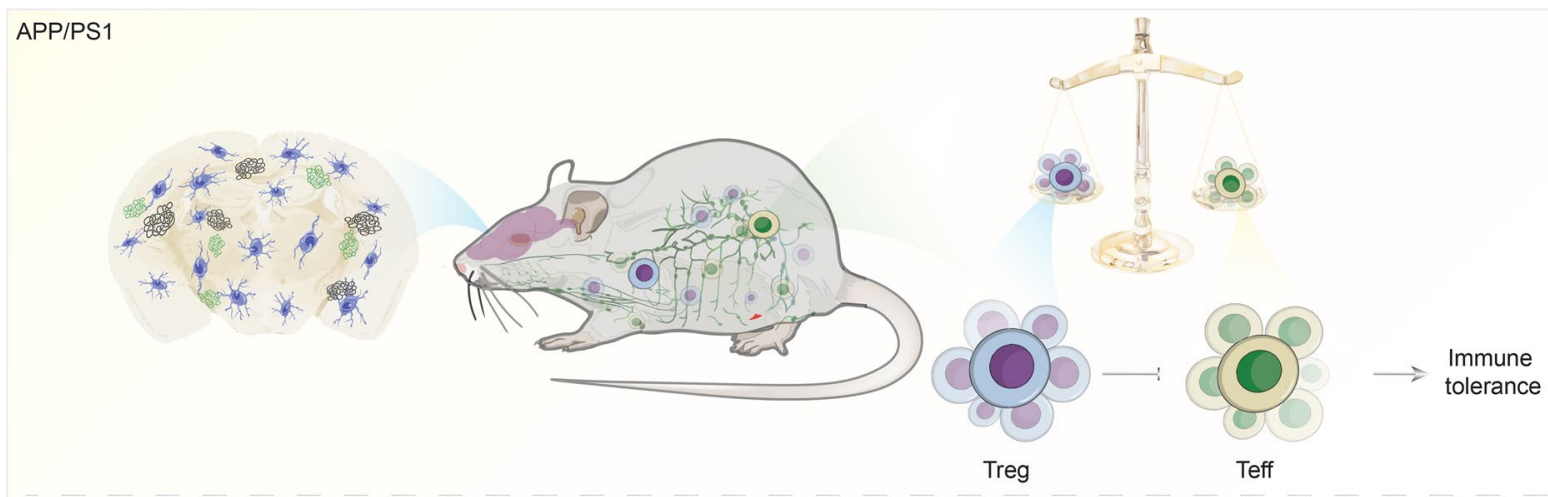

APP/PS1/AB-Th1
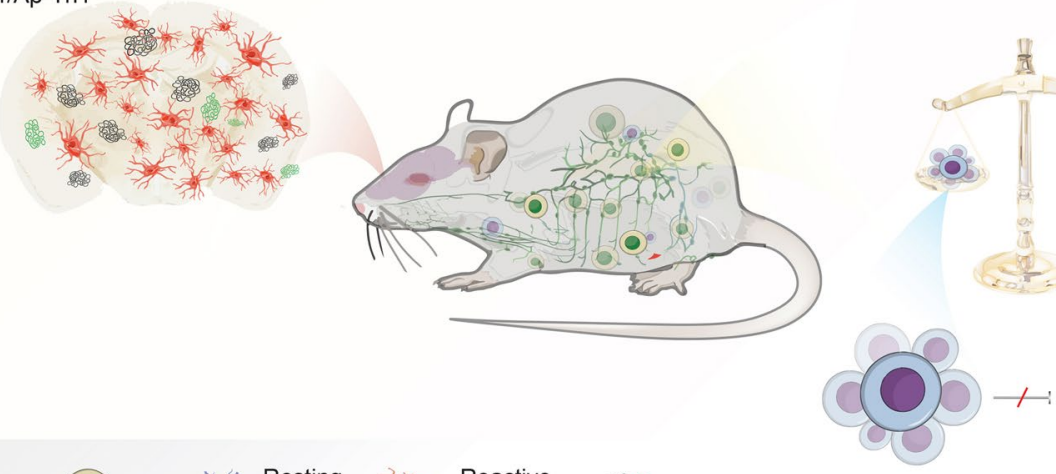

Treg

impairment

Teff

\section{Background}

Alzheimer's disease (AD) is the most common form of age-associated dementia and has become the sixth leading cause of death in the United States $[1,2]$. AD is characterized by the presence of misfolded self-proteins. Those self-proteins include amyloid beta $(A \beta)$ and hyperphosphorylated tau present within the brain and the systemic circulation $[3,4]$. A $\beta$ and tau aggregate and deposit among brain tissues as senile or amyloid plaques and neurofibrillary tangles. In addition, neuroinflammation persists and has been identified as a key disease-driving factor $[2,5]$. Both innate and adaptive immunity play disease-propagating roles $[2,6,7]$. Central nervous system (CNS) innate microglial cells and astrocytes are activated by the disease proteins and contribute to neuronal injuries by producing inflammatory and neurotoxic factors. These increase aberrant amyloid precursor protein (APP) cleavage, $\mathrm{A} \beta$ production, and tau phosphorylation $[8,9]$. The role of adaptive immune $\mathrm{T}$ cells in $\mathrm{AD}$ pathogenesis is under-reported and less well understood. We posit that understanding disease-linked adaptive immunity will permit the harnessing of peripheral immune $\mathrm{T}$ cell responses to facilitate $\mathrm{AD}$ therapeutic management.

The peripheral adaptive immune system, comprised of cytokine secreting T cells, monocytes, and B lymphocytes, is activated by modified self-peptide fragments, such as $A \beta$ and tau. These are engulfed and presented by antigen presenting cells (APCs) [2, 10]. T cell subsets contribute either effector or regulatory functions that are maintained during homeostatic conditions to maintain immunological tolerance. However, in pathological states, effector $\mathrm{T}$ cell (Teff) subsets react against misfolded and disease-specific self-proteins that can break immune tolerance and expand self-reactive $\mathrm{T}$ cells $[2,11$, 12]. Clonal expansion of CD8+ Teffs in both the periphery and CNS has been shown in AD patients [13]. Similarly, elevated CD4+ Teffs are reported in AD patients with mild cognitive impairment [14-16]. Additionally, CD4+ Teff subsets reactive against AD-associated pathological proteins that included $A \beta$-reactive type 1 
T helper (Th1), type 2 Th (Th2), and type 17 Th (Th17) cells were studied in mixed microglia-astroglia cultures. These studies demonstrated that glial pro-inflammatory responses are driven by Th1 and Th17 and regulated by Th2 cells [17]. Among A $\beta$ responsive Th1, Th2, and Th17 cells, only interferon gamma (IFN $\gamma$ )-secreting Th1 cells accelerate disease in double transgenic mice expressing chimeric mouse/human amyloid precursor protein and mutant human presenilin 1 (APP/PS1). Disease can be corrected by passive transfer of anti-IFN $\gamma$ antibodies [18]. In contrast, protective effects of intracerebroventricularly injected A $\beta$-specific Th1 cells in 5XFAD (C57BL6) mice facilitate enhancement of microglial major histocompatibility complex class II (MHCII) and increased phagocytic activities $[19,20]$. Overall, the role played by CD4+ Teffs in $\mathrm{AD}$ pathogenesis remains incompletely understood. In this report, we investigated the role of Teffs in AD-associated brain pathologies by developing $\mathrm{A} \beta$-specific $\mathrm{CD} 4+$ Th1 and Th17 Teff clonal cell lines, used to study the role of $A \beta$-specific Teffs in $A D$ progression. The unique cytokine signature, transcription factor expression, and MHCII-IA ${ }^{\mathrm{b}}-\mathrm{A} \beta$ tetramer staining affirmed a distinctive cellular phenotype and antigen specificity. A $\beta$-reactive Th1 and Th17 Teffs, adoptively transferred into APP/PS1 mice demonstrated accelerated behavioral and pathological disease, thus supporting a role as disease perpetrators. This suggests an evolving role for CD4+ Teffs in $\mathrm{AD}$ progression with opportunities for therapeutic interventions by immune modulation.

\section{Results}

\section{$A \beta$-Th1 and $A \beta$-Th 17 cell phenotypes are stable}

Previous works developed antigen-specific $\mathrm{T}$ cells from $\mathrm{A} \beta_{1-42}$ immunization of non-transgenic (non-Tg) mice. However, those cells were polarized for a short period prior to adoptive transfer with uncertain phenotypes [18, 19]. Here, we developed stable A $\beta$-specific Teff clones that were maintained in culture for more than 6 months and retained antigen specificity and phenotype. Flow cytometric analysis for intracellular cytokines revealed that activated $\mathrm{A} \beta$-Th 1 cells expressed pro-inflammatory cytokines, interferon gamma (IFN $\gamma$ ) (44.1\%) and tumor necrosis factor alpha (TNF $)$ (52.3\%), and expressed nuclear transcription factor T-box expressed in $\mathrm{T}$ cells (Tbet) (85.6\%). A $\beta$-Th17 cells preferentially expressed interleukin 17 (IL17) (43.7\%) and transcription factor RAR-related orphan receptor gamma (RORY) (92.7\%) (Fig. 1a). To further confirm the cellular phenotype of $\mathrm{A} \beta$-Teffs, extracellular cytokine release was assessed by the immunoblot staining, which showed that $A \beta-T h 1$ cells selectively secreted IFN $\gamma$, while $A \beta-T h 17$ cells secreted higher levels of IL17 (Fig. 1b). Both $A \beta-T h 1$ and A $\beta$-Th17 cells secreted TNF $\alpha$ after activation, although higher expression was observed in $A \beta$-Th 1 cells. $A \beta$-Th1 and $\mathrm{A} \beta-\mathrm{Th} 17$ cells also upregulated chemokines CCL3 (MIP-1 $\alpha$ ) and CCL4 (MIP-1 $\beta$ ), but expression was 35\% higher in $A \beta-T h 1$ cells compared to $A \beta-T h 17$ cells. CCL3 and CCL4 have been implicated in different inflammatory conditions and are produced in substantial quantities by the Th1 type lymphocytes [21], further supporting the cellular phenotype of $A \beta$-Teffs. The unique $T$ cell receptor (TCR) recognizes cognate antigen when presented by the major histocompatibility complex type I or type II (MCH-I or -II) molecules of antigen presenting cells (APCs) $[2,10]$. To determine the antigen specificity of Teff clones, $A \beta-T h 1$ and $A \beta-T h 17$ cells were incubated with fluorescently labeled MHCII-IA ${ }^{\mathrm{b}}$-KLVFFAEDVGSNKGA tetramer. The 3 -month $A \beta-T h 1$ and $A \beta-T h 17$ clones showed binding with $\mathrm{MHC}$-peptide tetramer in a dose-dependent manner, confirming their $\mathrm{A} \beta$ specificity (Additional file 1: Fig. S1b). Prolonged maintenance of stable Teff clones (6 months) maintained their cognate antigen recognition seen through dose-dependent $A \beta-$ Teff-MHC-peptide binding in Fig. 2a comparable to the 3-month clones (Additional file 1: Fig. S1b).

To provide greater insight in parent Th1 clone interaction with $\mathrm{A} \beta$ peptide bound to MHCII-IA ${ }^{\mathrm{b}}, \mathrm{TCR} \alpha$ and TCR $\beta$ chain sequences were identified, and molecular modeling studies were performed with peptide-MHCII (pMHC) complex (Fig. 2b). Molecular modeling of full-length $\mathrm{TCR} \alpha / \beta$ complex with $\mathrm{A} \beta_{1-42}-\mathrm{MHCII}-\mathrm{IA}^{\mathrm{b}}$ (pMHCII) complex was performed to determine exact amino acid interactions between two complexes [22]. The model was constructed with structural assessment, validation for various features, bond orientation, and overall quality of model performed. pMHC complex consisted of MHCII-IA ${ }^{\mathrm{b}} \alpha$ (green chain), MHCII-IA ${ }^{\mathrm{b}} \beta$ (cyan chain), and $A \beta$ peptide (blue chain) (Fig. $2 b$ ). TCR complex consisted of TCR $\alpha$ (yellow chain) and TCR $\beta$ (red chain). The Ramachandran plot or the $\phi / \psi$ plot predicts the conformational stability of the models, the TCR-pMHC complex had a RC score of $98.35 \%$ for favored region and $0.44 \%$ for outliers suggested its good quality (Additional file 1: Fig. S2a(i,ii)). MolProbity score and the QMEAN score reflects overall quality of the model, herein they were 0.66 and -3.60 , respectively. The TCR-pMHC complex was subjected to molecular dynamics (MD) simulations and the final structure from the $100 \mathrm{~ns}$ MD trajectory was analyzed for its root-mean-square deviation (RMSD) and root-mean-square fluctuations (RMSF) for individual amino acid residues [23]. The RMSD during the MD simulation for whole complex gradually rose by $5 \AA$ from 2 to $7 \AA$ during the initial $40 \mathrm{~ns}$ and then converged to stabilize between $1.5 \AA$ ( 5.5 to $7 \AA$ ) for rest of the simulation (Additional file 1: Fig. S2a(iii)). The RMSF during the simulation was observed between 1 to 
a
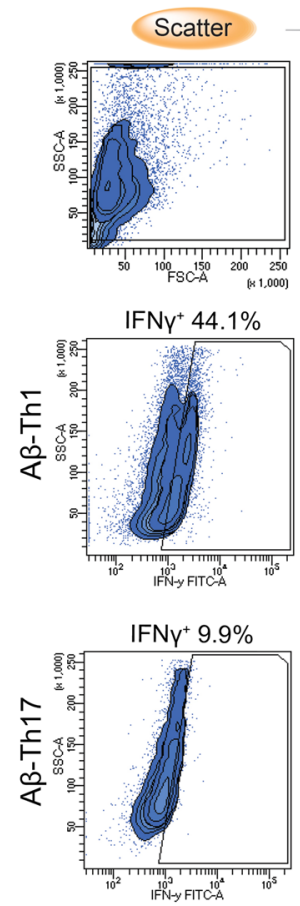
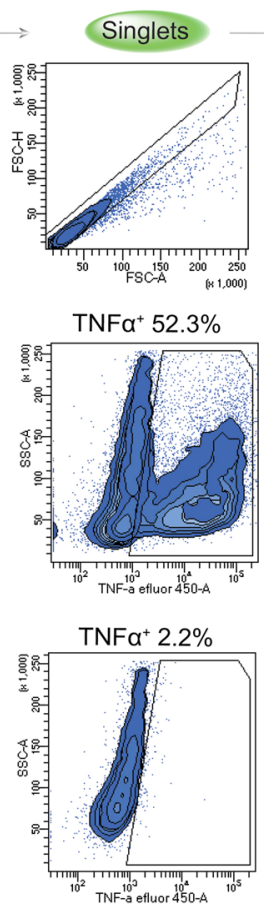
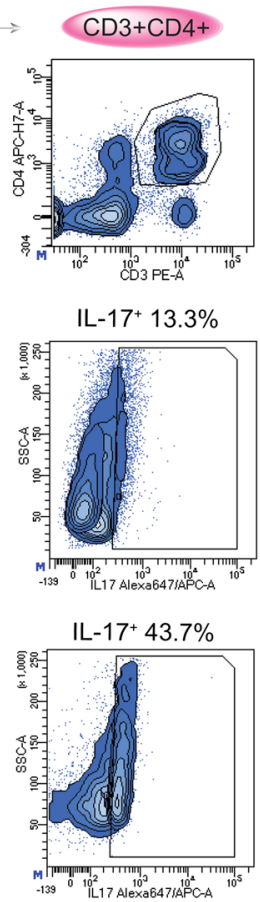

b
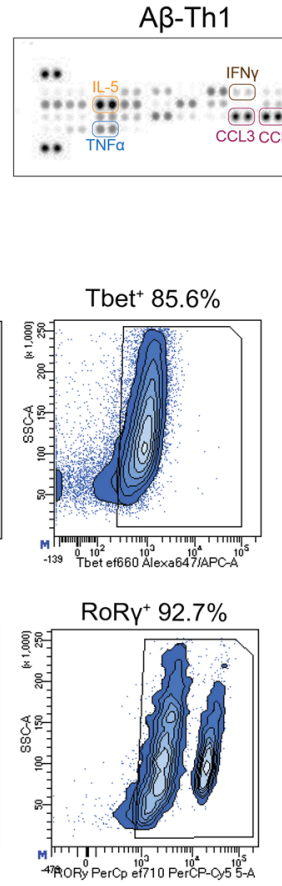
G-CSF
GM-CSF
CCL1 SICAM-

IFN- $y$
IL-1 $\alpha$

IL-1 $\alpha$

IL-1 ra
IL-3

IL-3
IL-4
IL-6

$\mathrm{IL}-6$
$\mathrm{IL}-10$
$\mathrm{IL}-13$

IL-13
IL-16
IL-17

$\mathrm{IL}-17$
$\mathrm{CXCL} 10$

$\mathrm{CXCL} 1$
$\mathrm{M}-\mathrm{CSF}$

$\mathrm{M}-\mathrm{CSF}$
$\mathrm{CCL} 2$

CCL12

CCL3

$\mathrm{CCL} 4$
$\mathrm{CXCL} 2$

CCL5

CXCL12

TIMP-1

TNF- $\alpha$
A $\beta-T h 17$

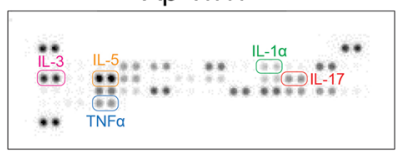

* TNFa

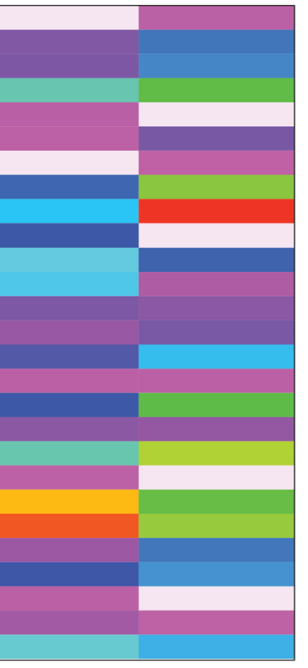

30000

$A \beta$-Th1 $\quad A \beta$-Th17

Fig. 1 Cellular phenotype of the $A \beta$-Th1 and A $A$-Th17 cells. a Flow cytometric analysis of intracellular cytokine and transcription factor expressed by $\mathrm{A} \beta$-Th1 and A $\mathrm{A}$-Th 17 cells that were maintained as clones for greater than 6 months. T cells were stimulated for $12 \mathrm{~h}$ with PMA and ionomycin in the presence of brefeldin A. $\mathbf{b}$ Representative immunoblot and quantification for 42 different cytokines and chemokines extracellularly secreted from $A \beta-T h 1$ and $A \beta-T h 17$ cells after stimulation with PMA and ionomycin

$14 \AA$ with most of the residues having RMSF between 1 to $3 \AA$ (Additional file 1: Fig. S2a(iv)). The individual components of the complex were studied and the RMSF for each component was analyzed. MHC $\alpha$ and MHC $\beta$ are green and cyan colored ribbons, respectively (Fig. 2b(i)), MHC $\alpha$ had RMSF of $3 \AA$ for N-terminal Met1 and about $2 \AA$ for C-terminal Glu73 (Additional file 1: Fig. S3b(ii)), the residues belonging to the loop regions (residues $40-45$ ) had very high RMSF of about $8.5 \AA$. The MHC $\beta$ had RMSF of $2.25 \AA$ for N-terminal Met257 and about $4.5 \AA$ for C-terminal Gln521 (Additional file 1: Fig. S2b(iii)). A $\beta$ peptide $\mathrm{N}$-terminal residue Asp522 and C-terminal residue Ala563 showed interactions with MHC and TCR molecules (Fig. 2b(i)). Stabilized fluctuations and formation of multiple interactions between peptide-MHC and pMHC-TCR are shown under the surface diagram (Fig. 2c(i)). MHC $\alpha$ and $M H C \beta$ showed multiple interactions with $\mathrm{A} \beta$ peptide; Ala563 of peptide interacted with Arg168 of MHC $\alpha$ chain and Arg322 of MHC $\beta$ chain to form donor-receptor pair leading to hydrogen bonds formation (Fig. $2 c(i i)$ ). $A \beta$ residue Lys549 formed hydrogen bond interaction with backbone

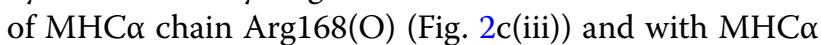

chain Asp169(OD2) (Fig. 2c(iv)). TCR chains were analyzed for their RMSF; TCR $\alpha$ chain showed higher fluctuations of around $6 \AA$ owing to terminal residues, but TCR $\beta$ chain had lower RMSF between 1 and $3 \AA$ for most of the residues with the terminal residues showing about $10 \AA$, which was expected for the terminal helixes. The Fab (fragment antigen binding) region showed lower RMSF due to its complexation with pMHC molecule (Additional file 1: Fig. S2b(i-iii)). pMHC molecule predominantly interacted with TCR $\beta$ chain and formed multiple interactions; pMHC sidechain residues Glu543 and Ser547 formed hydrogen bonds with Tyr908, Asp953 and Gln952 of TCR $\beta$ (Fig. 2c(v)). pMHC residue His535 (NE2) formed hydrogen bond with $\operatorname{Asn}(\mathrm{O})$. His535 (O) interacted with Tyr956 $(\mathrm{OH})$ to form intermolecular hydrogen bonding and due to stacking of the aromatic rings Tyr956 and His535 also showed $\pi-\pi$ interactions (Fig. 2c(vi)); pMHC peptide residue Glu532 also interacted with TCR $\beta$, Glu532(OE2)-Tyr961(OH) and Glu532 (OE1)-His886(NE2) (Fig. 2c(vii)). Higher fluctuations in both TCR $\alpha$ and TCR $\beta$ chains were observed for the Fc (fragment crystallizable) regions, which were attributed to the helices that form $\mathrm{C}$-terminals of TCR $\alpha$ and TCR $\beta$ 


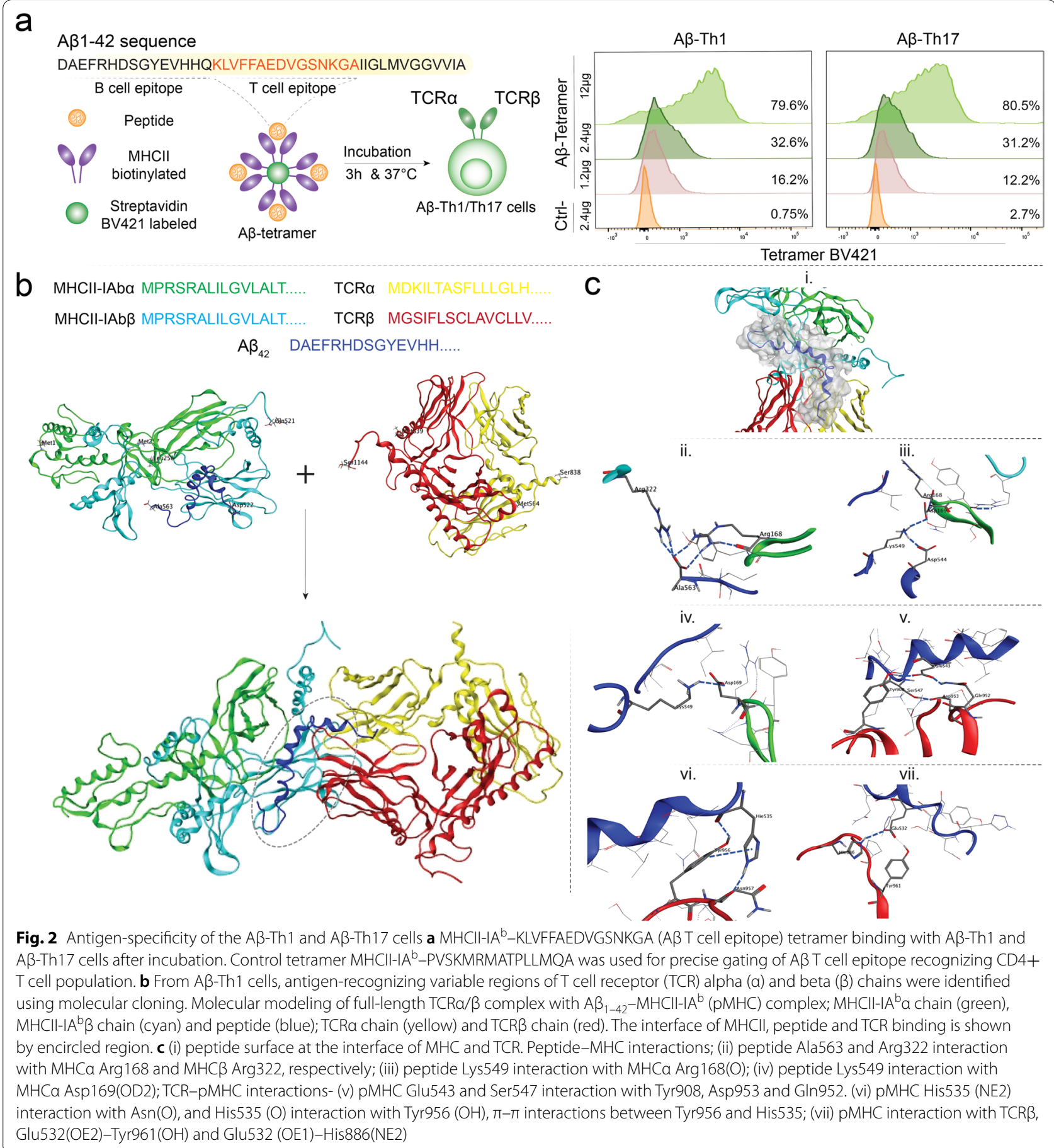

chains (Additional file 1: Fig. S2c(i-v)). The overall TCRpMHC model suggests interaction of $A \beta$ peptide in the region between residues Glu532 to Ala563 with MHC molecule and TCR Fab region, with rest of the peptide having very less to no interactions during the MD simulation of the complex.

\section{Adoptive transfer of $A \beta$-Teffs accelerates memory impairment in mice}

To test the behavioral effects of A $\beta$-Teffs, $2 \times 10^{6} \mathrm{~A} \beta$-Th1 or $\mathrm{A} \beta-\mathrm{Th} 17$ cells were adoptively transferred to APP/ PS1 mice in 2 weekly doses and recipients were evaluated for spatial learning and memory in the radial arm water maze (RAWM) test 2 weeks after second adoptive 
transfer (Fig. 3a). APP/PS1 mice showed signs of memory impairment evidenced by significant increases in the number of errors in late retention trial T5 $(p<0.05$, block-1 and block-3) compared to non-Tg mice (Fig. 3b) and were consistent with our previous reports [6]. Higher number of memory errors were observed in APP/PS1 recipients that received either $A \beta-T h 1$ or $A \beta-T h 17$ cells compared to non-Tg mice $(\mathrm{A} \beta-\mathrm{Th} 1 p<0.01$ in block-1 and $p<0.001$ in block- 3 while $\mathrm{A} \beta$-Th17 $p<0.01$ in block3). Additionally, APP/PS1 mice that received A $\beta$-Teffs exhibited 30\% greater number of experimental errors compared to untreated APP/PS1 mice, but were not significantly different. Overall, these results support the notion that $A \beta-T h 1$ and $A \beta-T h 17$ Teffs increase memory impairment development speed in APP/PS1 mice and is linked to a pro-inflammatory phenotype under an amyloid enriched environment.

Alteration in brain glucose uptake and its subsequent metabolism is a biomarker for memory impairment [24, $25]$, and has been used to confirm the effects of $A \beta$-Teffs

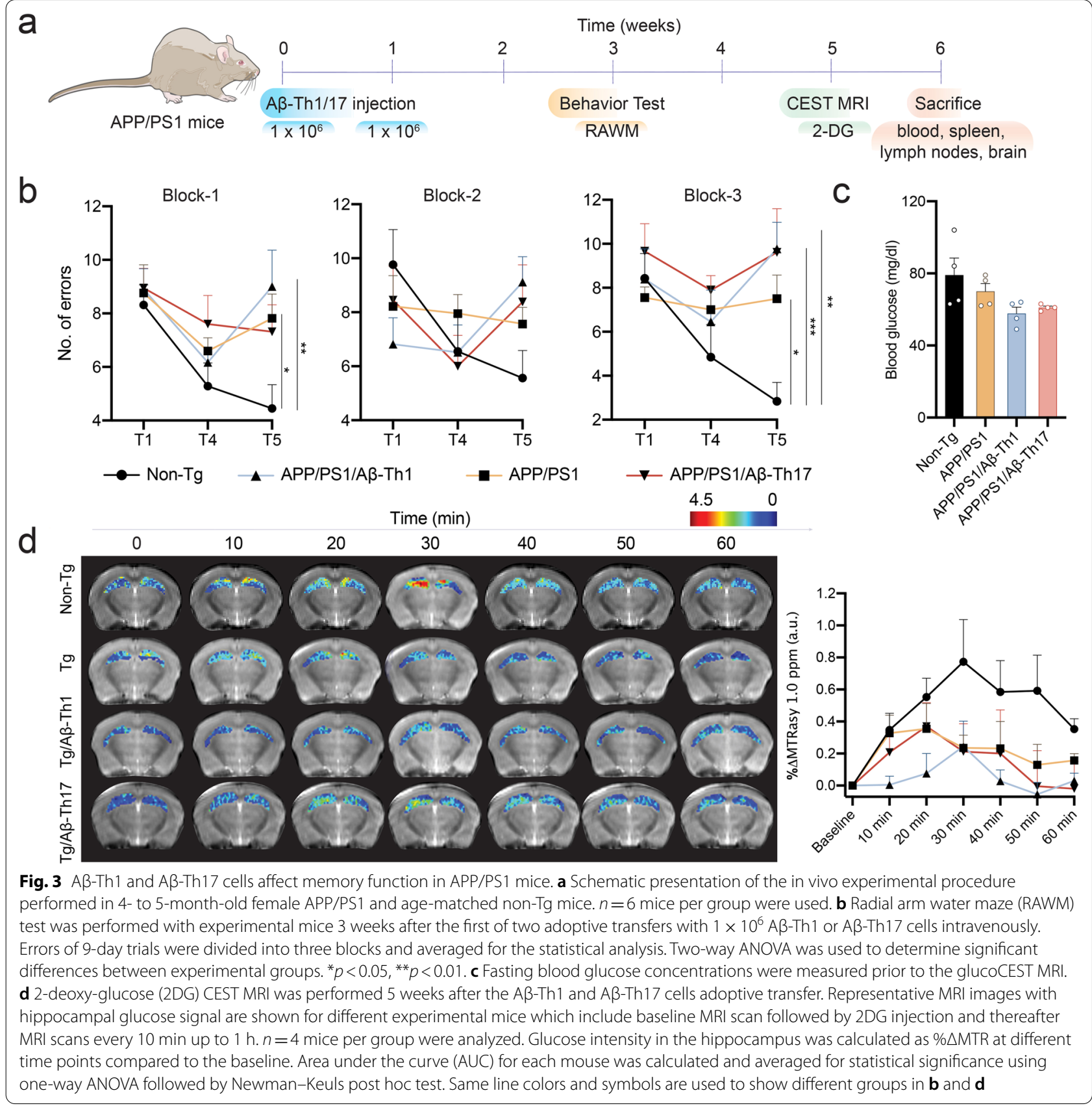


on the memory functions of APP/PS1 mice. ${ }^{18} \mathrm{~F}$-radiolabeled fluorodeoxyglucose $\left({ }^{18} \mathrm{~F}-\mathrm{FDG}\right)$ positron emission tomography (PET) imaging is commonly used for the diagnosis of dementia stage in the AD patients $[26,27]$ and in laboratory animal models $[28,29]$, whereas nonradiolabeled 2-deoxy glucose (2DG) chemical exchange saturation transfer (CEST)-MRI has been shown to assess the glucose uptake in AD animal models with better resolution [30]. 2DG can quickly enter the brain via the same transporters for the $\mathrm{D}$-glucose, where it is metabolized into 2DG-6-phosphate (2DG6P), but minimally metabolized further. Due to low blood-brain barrier (BBB) permeability, 2DG6P is trapped inside the brain that allows assessment of glucose uptake by the CEST-MRI approach as described earlier [31]. Prior to glucoCEST, fasting blood glucose concentration was reduced in APP/ PS1 mice (11\%) compared to non-Tg mice, whereas concentrations in APP/PS1/A $\beta$-Th1 and APP/PS1/A $\beta$-Th17 mice decreased by $27 \%$ and $23 \%$, respectively (Fig. $3 \mathrm{c}$ ). Non-Tg mice showed highest 2DG uptake as glucoCEST signal in the hippocampus, a region that primarily drives the memory functions, and then slowly declined over more than $1 \mathrm{~h}$ as shown in the representative scans (Fig. 3d). APP/PS1 mice showed a low hippocampal glucoCEST signal compared to non-Tg mice. The area under curve (AUC) of glucoCEST for APP/PS1 mice was 55\% lower than non-Tg mice. The AUC was further reduced in APP/PS1/A $\beta$-Th1 mice $(p<0.01,87 \%)$. APP/PS1/ A $\beta$-Th17 mice showed $67 \%$ less AUC compared to non$\mathrm{Tg}$ mice. APP/PS1/A $\beta$-Th1 and APP/PS1/A $\beta$-Th17 mice decreased AUC $72 \%$ and $26 \%$, respectively, compared to untreated APP/PS1 mice, but did not achieve significance. Thus, A $\beta$-Teffs decreased glucose uptake in the hippocampus region of APP/PS1 mice paralleled their abilities to accelerate memory impairment.

\section{$A \beta$-Teffs promote systemic inflammation}

The onset of systemic inflammatory responses has been demonstrated decades before memory impairment and subsequent neurodegeneration in AD [32]. Moreover, higher levels of serum inflammatory cytokines are observed in individuals who after 20 years demonstrated memory decline and decreased brain volume [33]. Such observations suggest that systemic inflammatory responses play an important early role in AD pathology before amyloid deposition and microglia activation in the brain $[2,14,15]$. To determine the effects of A $\beta$-Teffs on systemic inflammation, frequencies of different $\mathrm{T}$ cell subsets and inflammatory cytokines were measured in blood, spleen and lymph nodes after adoptive transfer. Although, frequencies of CD4+ and CD8+ T cells were unchanged regardless of mouse strain or treatment (Additional file 1: Fig. S3), the subset analysis revealed increased systemic pro-inflammatory markers. It was hypothesized that systemic inflammatory responses predominantly arise from antigen-specific $T$ cells present in the periphery of experimental mice. Therefore, we tested the frequency of $A \beta$ reactive $C D 4+T$ cells by stimulating lymph node cells with cognate antigen $(\mathrm{A} \beta)$ in presence of APCs. CD4+ T cells from non-Tg mice showed very low binding with MHCII-peptide tetramer, suggesting the presence of few $\mathrm{A} \beta-\mathrm{CD} 4+\mathrm{T}$ cells during homeostasis (Fig. 4a). In untreated APP/PS1 mice, A $\beta$-CD4+ $\mathrm{T}$ cell frequency was slightly, though insignificantly, higher compared to non-Tg mice (Fig. 4a). However, APP/PS1/A $\beta$-Th1 and APP/PS1/A $\beta-T h 17$ mice exhibited significantly higher levels of $\mathrm{A} \beta-\mathrm{MHCII}$ tetramer reactive $\mathrm{CD} 4+\mathrm{T}$ cells compared to non-Tg and APP/ PS1 mice $(p<0.01)$. The results indicate that antigenrecognizing $\mathrm{CD} 4+\mathrm{T}$ cell populations are sustained after adoptive transfer of $A \beta$-Teffs and suggested a contributory role in systemic inflammation associated with $\mathrm{AD}$. Indeed, splenocytes isolated from APP/PS1/A $\beta-T h 1$ and APP/PS1/A $\beta$-Th17 mice and stimulated with phorbol12-myristate-13-acetate (PMA) and ionomycin secreted significantly higher levels of pro-inflammatory cytokines TNF $\alpha(p<0.05)$ and IL17 $(p<0.001)$ compared to splenocytes isolated from non-Tg and untreated APP/PS1 mice (Fig. 4b). Additionally, APP/PS1/A $\beta$-Th1 mice secreted significantly higher levels of IFN $\gamma(p<0.05)$ compared to non-Tg and untreated APP/PS1 mice. Compared to non-Tg controls, no differences in CD4+Tbet $+\mathrm{T}$ cell frequencies from APP/PS1 mice in any lymphoid compartment were detected, while CD4+ROR $\gamma+\mathrm{T}$ cell frequency was significantly increased in spleens of APP/ PS1 mice $(p<0.05)$ (Fig. 4c). CD4+Tbet+ T cells were significantly elevated in spleen $(p<0.05)$ and lymph node $(p<0.01)$ of APP/PS1/A $\beta$-Th1 mice compared to non-Tg counterparts. Similarly, CD4+ROR $\gamma+\mathrm{T}$ cell frequencies were significantly increased in all tested lymphoid compartments of APP/PS1/A $\beta$-Th1 mice $(p<0.01)$ while in APP/PS1/A $\beta-T h 17$ mice, $C D 4+R O R \gamma+T$ cell frequencies were significantly increased in blood $(p<0.05)$ and spleen $(p<0.01)$ compared to non-Tg mice. In lymph nodes, APP/PS1/A $\beta$-Th1 mice showed increased CD4+Tbet+ $(p<0.05)$ and CD4+ROR $\gamma+\mathrm{T}$ cells $(p<0.001)$ compared to APP/PS1 mice. Together, these results highlight the potential of $A \beta$-specific Teffs to contribute to exacerbation of a pro-inflammatory environment in $\mathrm{AD}$ progression.

\section{A $\beta$-Teffs affect Treg immunosuppression}

Because afferent $\mathrm{T}$ cell and Teff responses modulate regulatory $\mathrm{T}$ cell (Treg) frequency and function $[2,34$, $35]$, we assessed the effects of $A \beta$-Teffs on Tregs, which play important roles in the maintenance of immune 

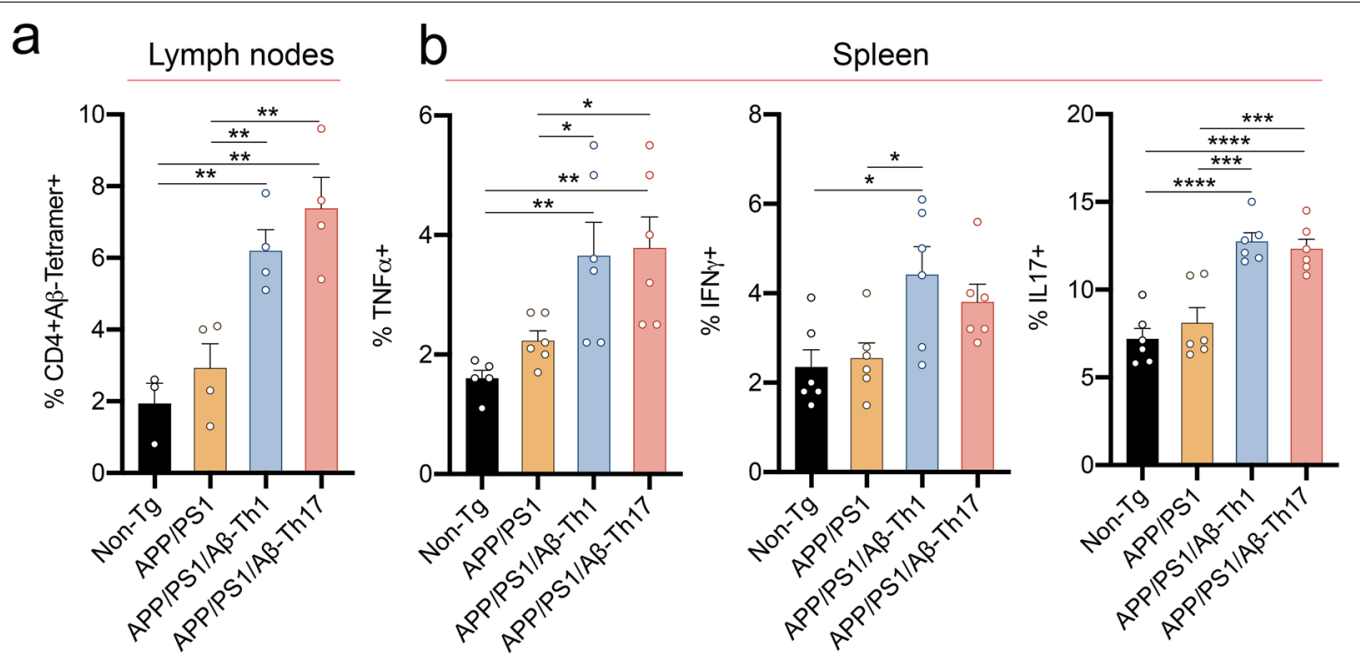

C

Blood

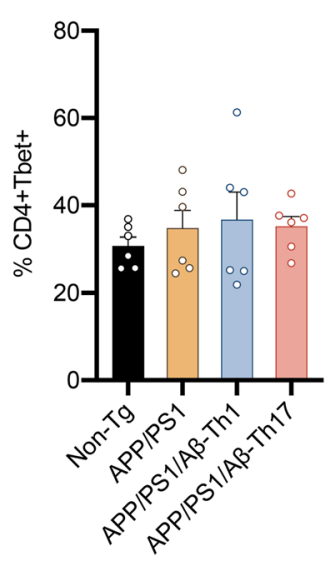

Spleen

Lymph nodes
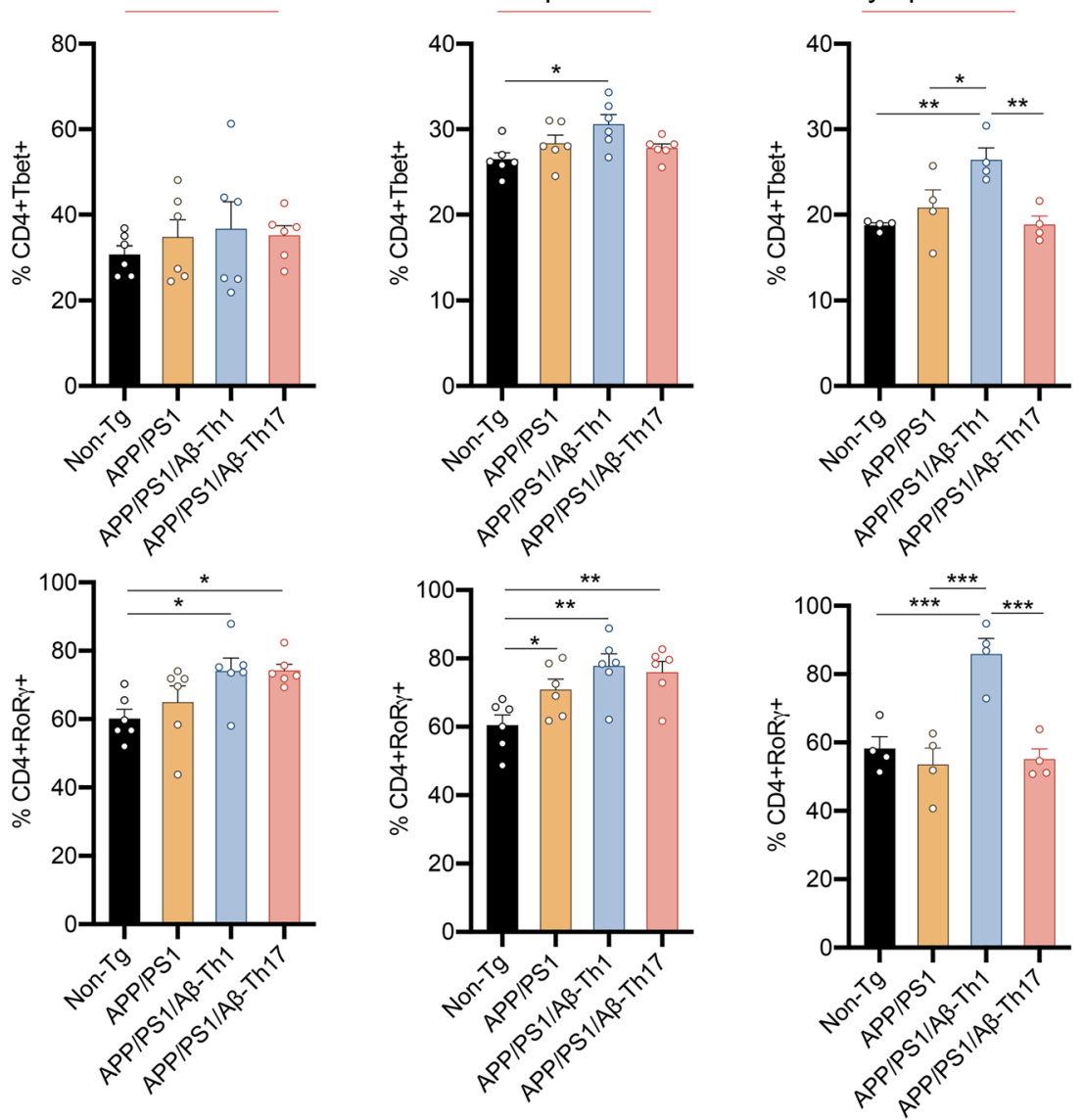

Fig. 4 Adoptive transfer A $\beta$-Teffs affect systemic inflammation in APP/PS1 mice. Experimental mice were killed 6 weeks after A $\beta$-Th1 and A 3 -Th17 adoptive transfer. a Frequency of $A \beta$ reactive $C D 4+T$ cells among lymph node cells after stimulation with $A \beta_{1-42}$ in presence of feeder cells using fluorescently labeled $\mathrm{MHCII-IA}$-peptide tetramer. $n=4$ mice per group were analyzed. $\mathbf{b}$ Frequency of intracellular pro-inflammatory cytokines TNFa, IFNY and IL 17 from splenocytes after stimulation with PMA and ionomycin in the presence of brefeldin A. $n=6$ mice per group were analyzed. c Frequency of CD4+Tbet + and CD4+RORy + T cells in blood, spleen and lymph nodes determined by flow cytometric analysis. $n=6$ mice per group were analyzed. One-way ANOVA followed by Newman-Keuls post hoc test was used to determine statistical significance. ${ }^{*} p<0.05$, ${ }^{* *} p<0.01,{ }^{* * *} p<0.001,{ }^{* * *} p<0.0001$ 
tolerance against self- and non-self-antigens [2, 36]. Tregs suppress disease-reactive pro-inflammatory $\mathrm{T}$ cell responses via their unique transcription factor forkhead box P3 (FOXP3) [6, 37]. Treg frequencies were identified using surface and intracellular markers CD4+CD25+FOXP3+ in different lymphoid compartments. APP/PS1 mice showed decreased frequency of CD4+CD25+FOXP3+ cells $(p<0.01)$ in spleen compared to non-Tg mice (Fig. 5a). However, APP/PS1/ $\mathrm{A} \beta$-Th1 mice showed decreased CD4+CD25+FOXP3+ $\mathrm{T}$ cell frequency in blood $(p<0.05)$, spleen $(p<0.001)$ and lymph nodes $(p<0.05)$ compared to non-Tg mice, and in spleen $(p<0.05)$ compared to APP/PS1 mice. As Treg frequency does not always correlate with immunosuppressive function $[38,39]$, we sought to determine the effects of A $\beta$-Teffs on the Treg-mediated function. Earlystage APP/PS1 mice (5-6 months old) showed slightly increased Treg function (14\%) compared to non-Tg mice at higher concentrations (1:1) which might be due to improved Treg function during early disease stages (Fig. 5b) [40]. However, APP/PS1/A $\beta$-Th1 mice showed significantly greater Treg dysfunction compared to nonTg (slope $p=0.3650$, intercept $p=0.002$ ) and APP/PS1 (slope $p=0.9954$, intercept $p<0.0001$ ) control mice at all concentrations. Similar Treg dysfunction was observed in APP/PS1/A $\beta$-Th17 mice at lower concentrations compared to Tregs from non-Tg and untreated APP/PS1 mice. Overall, results indicated that $A \beta-T h 1$ cells and to a lesser extent $\mathrm{A} \beta-\mathrm{Th} 17$ cells diminished Treg frequency and function and suggests that diminution of Treg medicated control contributes to increased pro-inflammatory environment and on leads to the breakdown of immune tolerance [41].

\section{A $\beta$-Teffs induce Th1-dominant inflammatory responses in the CNS}

We determined the effect of $A \beta$-Teffs on the expression of innate and adaptive immune genes within the CNS by using transcriptomic analysis of RNA from hippocampi of non-Tg and APP/PS1 mice treated with or without A $\beta$-Teffs. Gene expression of Treg transcription factor Foxp3 $(p<0.05)$ and anti-inflammatory cytokines $I l 10$ and $I l 13(p<0.05)$ and chemokine $C c r 8$ were diminished in APP/PS1/A $\beta$-Th 1 and APP/PS1/A $\beta$-Th 17 mice hippocampi compared to untreated APP/PS1 mice (Fig. $5 \mathrm{c}$ ), suggesting that adoptive transfer of $A \beta$-Teffs affect Tregs not only in the periphery, but also in the CNS. The inflammatory cytokine genes Il5, Il6, Ifng were decreased while Tnf was increased (1.43-fold) in APP/PS1/A $\beta$-Th1 compared to APP/PS1 mice (Additional file 1: Fig. S4). Importantly, Tbet encoding gene $T b \times 21$ expression increased in APP/PS1/A $\beta$-Th1 (2.59-fold) and APP/PS1/ A $\beta$-Th17 (1.32-fold) compared against APP/PS1 mice.
Notably, ROR $\gamma$ encoding gene Rorc expression decreased compared to non-Tg mice (Fig. 5c), underscoring predominate Th1 phenotype immune responses operative in the brains of A $\beta$-Teffs-treated APP/PS1 mice.

Adoptive transfer of $\mathrm{A} \beta$-Teffs into APP/PS1 mice were studied for their abilities to induce changes in selected biological processes. To elucidate these, functional and pathway enrichment analyses were performed in mice treated with $A \beta-T h 1$ or $A \beta-T h 17$ cells then compared to non-Tg and APP/PS1 controls. Compared to non-Tg mice, Kyoto Encyclopedia of Genes and Gnomes (KEGG) analysis of APP/PS1, APP/PS1/ $\mathrm{A} \beta-T h 1$ and $\mathrm{APP} / \mathrm{PS} 1 / \mathrm{A} \beta-T h 17$ mice demonstrated alterations in the cytokine-cytokine receptor interactions, IL17, TNF, chemokines, Toll-like receptor (TLR), Th17 cell differentiation, antigen processingpresentation, and Jak-STAT signaling pathways. There was greater enrichment of the TLR signaling pathway in $\mathrm{APP} / \mathrm{PS} 1 / \mathrm{A} \beta-T h 1$ mice. APP/PS1/A $\beta$-Th 17 mice showed higher Th1, Th2, and Th17 cell differentiation pathways compared to APP/PS1 controls (Fig. 5d). These data, taken together, suggest that chronic CNS inflammatory responses are induced by $A \beta-T h 1$ and A $\beta-17$ cells. APP/PS1/A $\beta$-Th17 mice also showed an enrichment of nuclear factor-kappa $B$ (NF-kB) signaling pathway, which serves as a central mediator of inflammation because promoter regions of several proinflammatory molecules have been found to contain the DNA binding site for NF- $\mathrm{KB}$ [42]. Reactome analysis of different $\mathrm{AD}$ groups compared to non-Tg mice showed enrichment of cytokine signaling in immune system with higher induction in APP/PS1/A $\beta$-Th 17 mice, while Search Tool for the Retrieval of Interacting Genes/Proteins (STRING) analysis showed enrichment of networks such as TLR signaling pathway; regulation of TNFR1 signaling, T cell chemotaxis; CC chemokine receptor 5, Toll/IL1 receptor homology (TIR) domain; and IL1-mediated signaling pathways with higher enrichment in APP/PS1/A $\beta$-Th1 mice compared to untreated APP/PS1 mice. Compared to untreated APP/ PS1 mice, KEGG analysis showed enrichments of Th1, Th2, and Th17 cell differentiation, Jak-STAT, TCR, and cytokine-cytokine receptor pathways in APP/PS1/ $A \beta$-Th1 mice, while IL17 signaling was enriched in APP/PS1/A $\beta$-Th17 mice (Fig. 5e). Th1, Th2 and Th17 cells are critical mediators of neuroinflammatory diseases and have been associated with the pathogenesis of several autoimmune diseases [43]. Reactome Gene Set Enrichment Analysis (GSEA) analysis showed enrichment of cytokine signaling in APP/PS1/A $\beta$-Th1 and APP/PS1/A $\beta-T h 17$ mice compared to untreated APP/PS1 controls. These data indicated enhanced cytokine mediated pathogenesis in $A \beta$-Teff-treated 


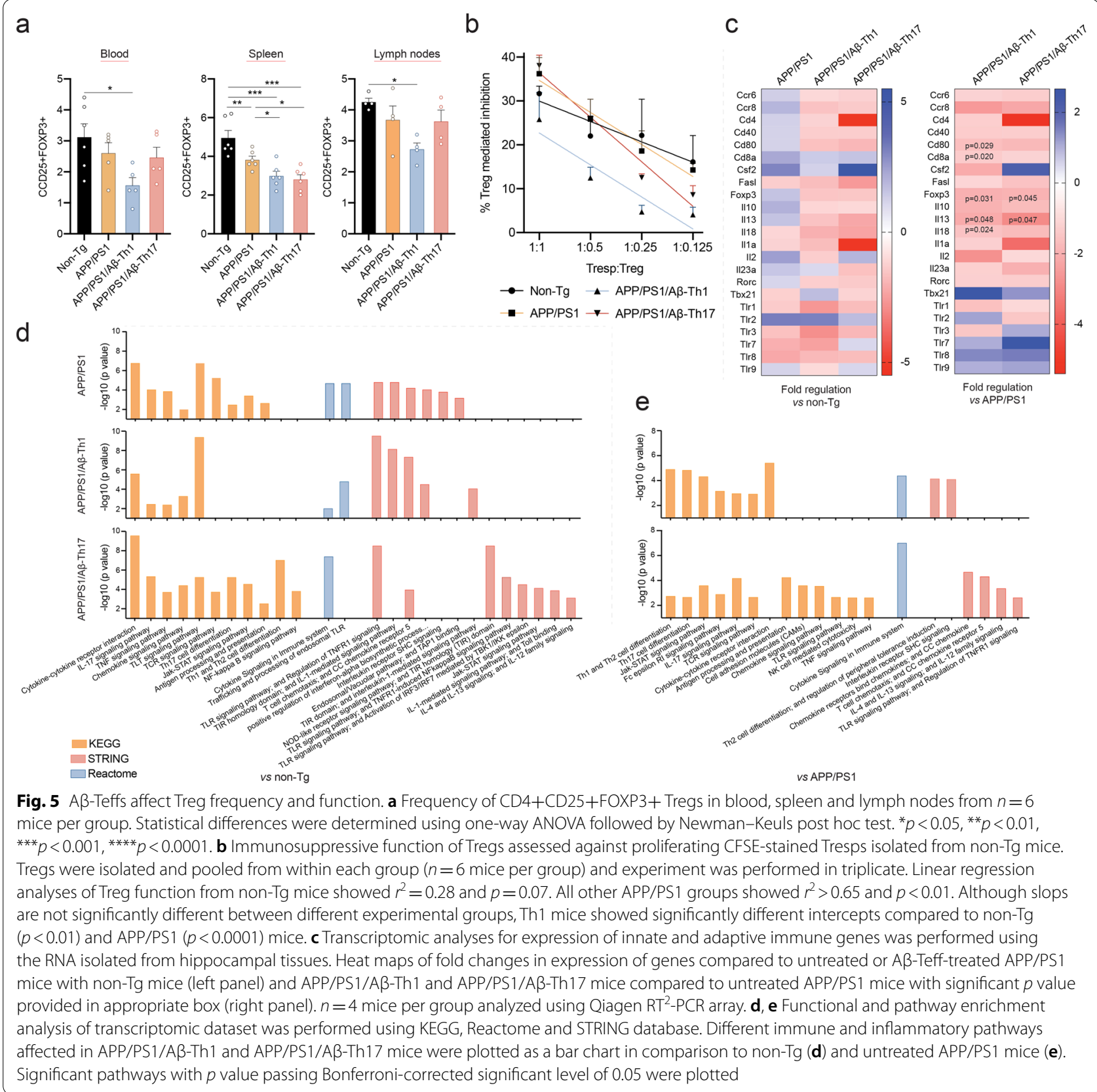

mice. Additionally, STRING analysis showed enrichment of immune-related networks of interacting genes in $A \beta$-Th 1 and $A \beta$-Th17-treated mice compared to untreated APP/PS1 mice. These data indicate that activated immune and inflammatory responses are exacerbated in $A \beta$-Teff adoptive transferred mice when compared to non-Tg and APP/PS1 controls.

\section{A $\beta$-Th 1 cells facilitate amyloid deposition}

Amyloid plaque forms upon sequential cleavage of APP attributed to different secretase enzyme activities. Before assessment of amyloid, we determined the effects of $A \beta$-Teffs on expression of full-length APP. Western blot analysis showed unaltered expression of full-length APP assessed by $6 \mathrm{E} 10$ and $22 \mathrm{C} 11$ in all APP/ PS1 mice irrespective of $A \beta$-Teffs treatment (Fig. 6a). As amyloid plaque develops by aggregation of soluble $A \beta$ oligomers, which are toxic and contribute to memory 
impairment [6], we next assessed the expression of soluble human $A \beta_{1-40}$ and $A \beta_{1-42}$ levels in cortical brain tissues from APP/PS1 mice. $A \beta_{1-40}$ levels significantly increased in APP/PS1/A $\beta$-Th1 $(p<0.01)$ and APP/PS1/ $\mathrm{A} \beta$-Th17 $(p<0.01)$ mice compared to untreated APP/ PS1 mice (Fig. 6b). Similarly, $A \beta_{1-42}$ levels significantly increased in APP/PS1/A $\beta$-Th1 $(p<0.05)$ and APP/PS1/ A $\beta$-Th17 $(p<0.05)$ mice compared to APP/PS1 mice. APP/PS1 mice develop amyloid plaque in the brain as early as 3 months of age [44], therefore we evaluated the effects of $\mathrm{A} \beta$-Teffs on the amyloid plaque deposition in mice brain by immunohistochemistry which showed remarkable increases in amyloid plaque deposition in A $\beta$-Teffs-treated APP/PS1 mice (Fig. 6c). Indeed, total amyloid plaque loads increased in both cortex (53\%) and hippocampus $(p<0.05)$ of APP/PS1/A $\beta$-Th1 mice compared to those of untreated APP/PS1 mice. APP/PS1/ $\mathrm{A} \beta$-Th17 mice showed total amyloid plaque loads $32 \%$ and $37 \%$ greater than APP/PS1 controls in cortex and hippocampus, respectively, but did not attain significance. The area occupied by the dense amyloid plaques was determined by Thioflavin-S staining of the same brain sections used for immunohistochemistry from different APP/PS1 mice. APP/PS1/A $\beta$-Th1 mice showed

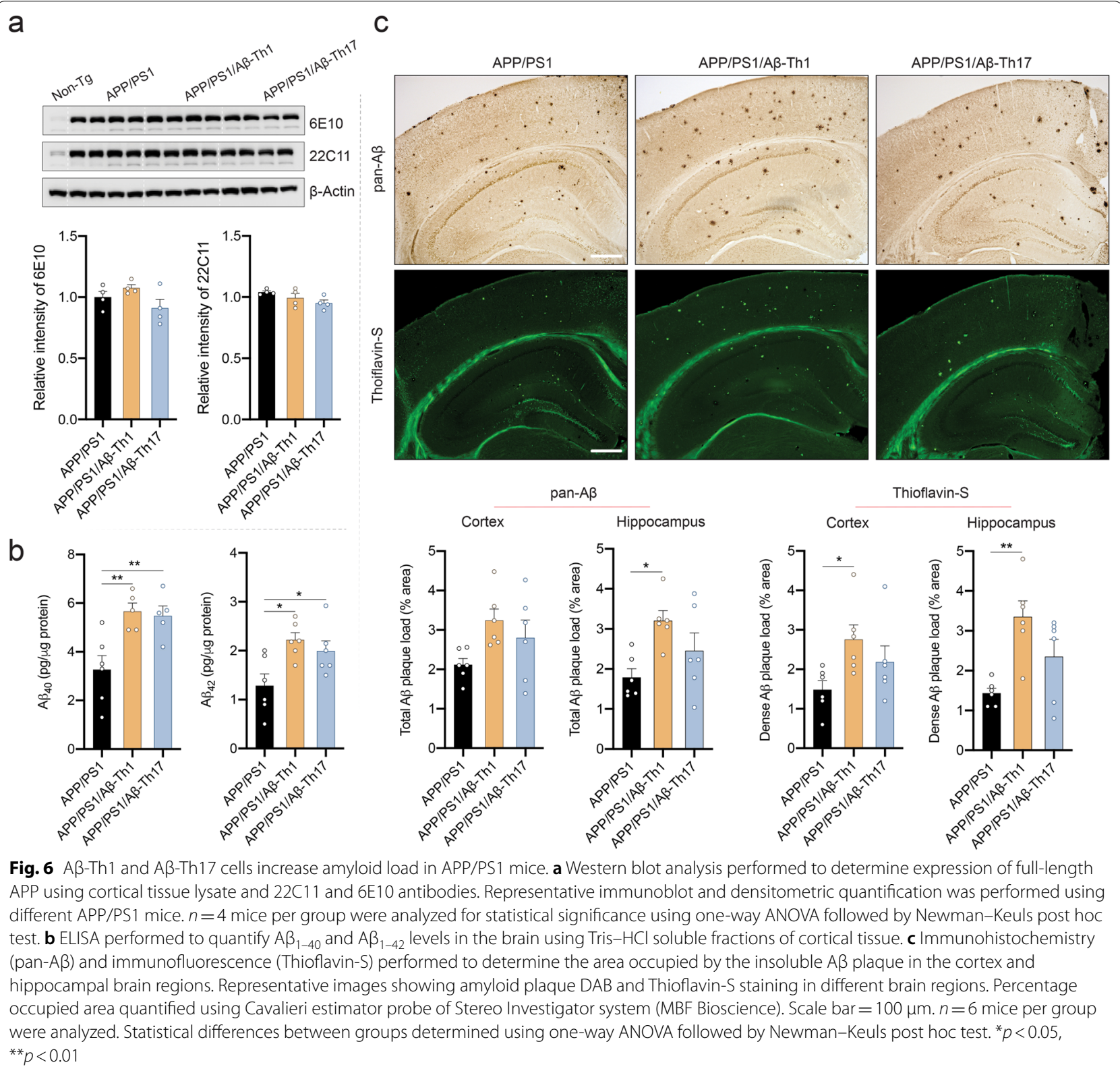


significantly increased dense amyloid plaque loads in cortex $(p<0.05,86 \%)$ and hippocampus $(p<0.01,134 \%)$ compared to APP/PS1 controls, while APP/PS1/A $\beta$-Th 17 mice showed dense amyloid plaque loads $47 \%$ and $64 \%$ higher than APP/PS1 controls in cortex and hippocampus, respectively, but without significance. The results highlight that A $\beta$-Teffs drive amyloidosis in the APP/PS1 mice brain via aberrant APP cleavage without affecting APP production.

\section{A $\beta$-Th1 cells activate microglia}

Microglia activation is a unique signature of neuroinflammation observed in AD patients and animal models [8], thus to determine the effects of $A \beta$-Teffs on microglial responses, we counted Iba1-reactive cells with amoeboid morphology in the cortex and hippocampus of different treatment groups. Immunohistochemistry visually showed that untreated APP/PS1 mice exhibited substantially more Iba1 positive (Iba1+) amoeboid cells compared to non-Tg mice suggesting microglial activation in early-stage AD mice (Fig. 7a). Moreover, remarkable numbers of reactive microglia were also observed in cortex and hippocampus of APP/PS1/A $\beta$-Th1 and APP/ PS1/A $\beta$-Th17 mice. Stereological quantification revealed significantly increased numbers of Iba1+-reactive microglia in the cortex $(p<0.01)$ and hippocampus $(p<0.01)$ of untreated APP/PS1 mice brain compared to non-Tg mice (Fig. 7b). APP/PS1/A $\beta$-Th1 mice showed higher microglia activation in the cortex and hippocampus $(p<0.01)$ even compared to untreated APP/PS1 mice. APP/PS1/ A $\beta$-Th17 mice also exhibited levels of reactive microglia in the cortex and hippocampus that were $16 \%$ and 29\% higher, respectively, than untreated APP/PS1 mice, but did not attain statistical significance. To gain greater insights into microglia activation states, expression of the classical (M1) and alternative (M2) microglia activation markers inducible nitric oxide synthase (iNOS) and arginase-1, respectively $[6,9]$ was assessed in cortical tissues from experimental mice by western blot analysis. In early-stage disease of APP/PS1 mice, iNOS levels were elevated and arginase-1 levels diminished, though not statistically compared to non-Tg mice (Fig. 7c). However, APP/PS1/A $\beta$-Th1 mice showed increased production of iNOS, while adoptive transfer of $A \beta-T h 1$ or $A \beta-T h 17$ Teffs significantly reduced arginase- 1 levels in recipient APP/PS1 mice $(p<0.05)$. These results revealed that $\mathrm{A} \beta$-Teffs adoptive transfer potentiates progressive proinflammatory (M1) microglia activation status in APP/ PS1 mice brain, wherein $A \beta$-Th1 cells are more capable of affecting microgliosis than $\mathrm{A} \beta$-Th17 cells.

\section{$A \beta$-Th 1 cells affect neuronal progenitor cell numbers and function}

Hippocampal neurogenesis correlates with memory function and neural plasticity; all affected during $\mathrm{AD}$ progression $[45,46]$. To examine the effects of $A \beta$-Teffs on neurogenesis during $\mathrm{AD}$ progression, we assessed doublecortin (Dcx) as a biomarker of neuronal progenitors of the hippocampus $[6,45]$. Dcx + cell frequency was significantly diminished by $72 \%$ in the dentate gyrus of untreated APP/PS1 mice brain compared to non-Tg mice $(p<0.001$, Fig. 8a). Adoptive transfer of A $\beta$-Teffs further reduced numbers of Dcx + progenitors, compared to non-Tg controls $(p<0.001)$, but were not significant compared to APP/PS1 mice (32\%). Next, we assessed expression of presynaptic (synaptophysin) and postsynaptic [postsynaptic density protein 95 (PSD95)] neurons in cortical brain lysates by western blot analysis. Co-expression of both pre- and post-synaptic proteins is essential for neuroplasticity, and therefore alteration of either protein level affects memory [6, 47]. Immunoblot quantification revealed that synaptophysin and PSD95 levels were unaltered in untreated APP/PS1 mice compared to nonTg mice (Fig. 8b). However, expression of synaptophysin was reduced in APP/PS1/A $\beta$-Th1 (27\% not significant) and APP/PS1/A $\beta$-Th17 $(p<0.05,45 \%)$ mice compared to non-Tg mice. Additionally, APP/PS1/A $\beta-T h 1(p<0.05)$, but not APP/PS1/A $\beta$-Th17 mice showed reduced expression of PSD95 compared to non-Tg mice. Thus, only presynaptic protein abnormalities were observed in APP/ PS1/A $\beta$-Th17 mice, while pre-and post-synaptic protein densities were affected in APP/PS1/A $\beta$-Th1 mice. Overall, $A \beta-T h 1$ and $A \beta-T h 17$ cell-mediated exacerbation of neuronal synaptic disintegrity in amyloid-rich environments which contribute to A $\beta$-Teffs' potential to accelerate memory impairment in APP/PS1 mice.

\section{Discussion}

Previous studies demonstrated a spectrum of effects for $A \beta$-reactive Teffs in animal models and AD patients $[17-19,48,49]$. However, one of the limitations of those studies is that polyclonal Teffs used were short-term maintained ( 2 to 4 weeks), unstable, and prone to plasticity, which are not ideal for the study of $\mathrm{T}$ cell processes in $\mathrm{AD}$ and their underlying complex mechanism of actions. The polyclonal cells, unlike cloned populations, contain mixtures of several putative, but unexpressed phenotypes, which could overwhelm the population during the short culture time or possibly be eliminated. Therefore, we generated stable, long-lived $A \beta-T h 1$ and $A \beta-T h 17$ Teff clones, which were maintained for more than 6 months without compromising cytokine signatures and antigen specificities prior to use in in vivo experiments. Adoptive transfer of $A \beta-T h 1$ and $A \beta-T h 17$ Teffs exacerbated 


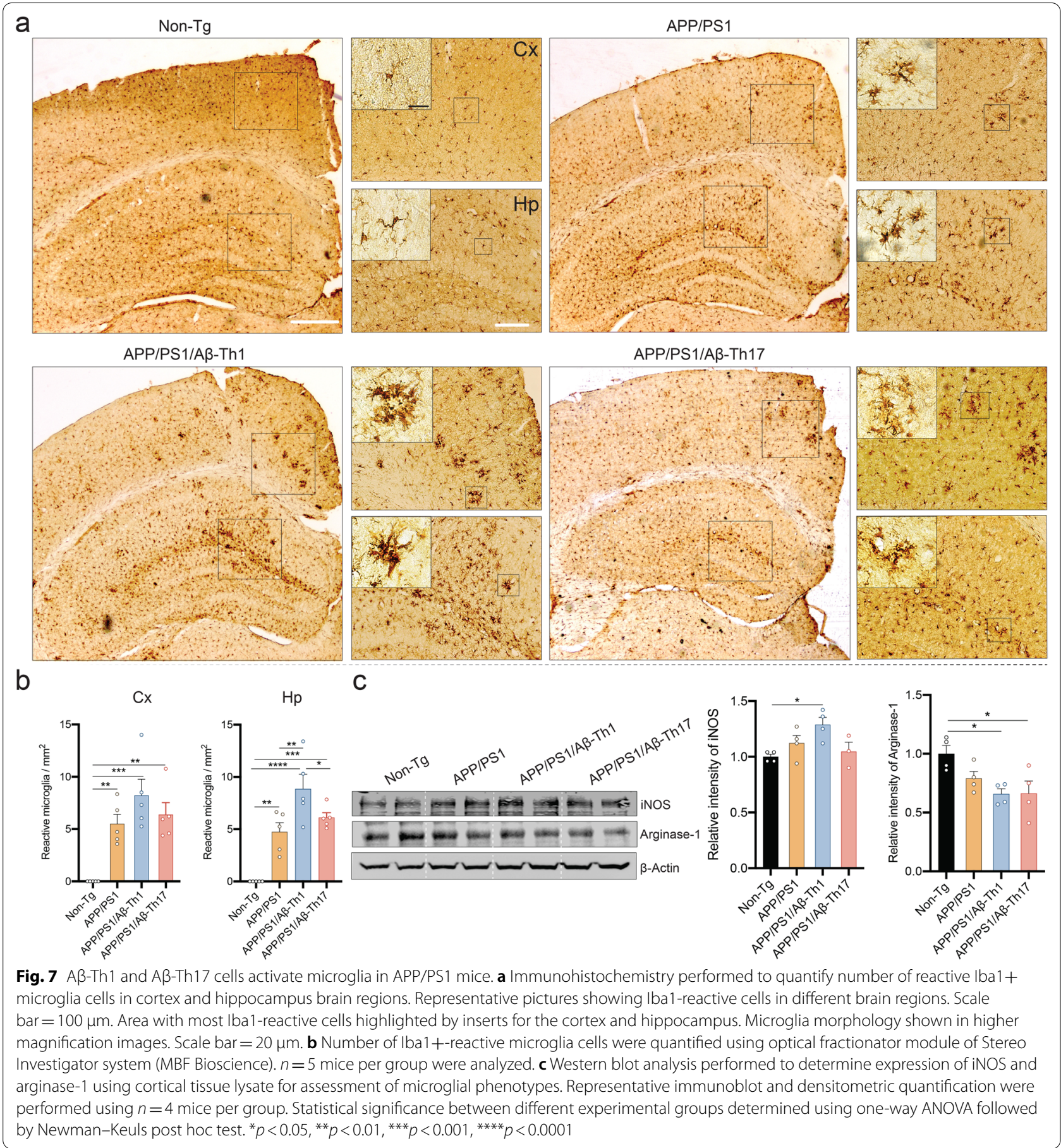

memory impairment and amyloid deposition in APP/PS1 mice. The results vary with a previous report where only IFN $\gamma$-secreting $A \beta$-Th 1 cells produced detrimental memory effects in APP/PS1 mice [18]. One possible explanation is that instead of independent development, we polarized $A \beta$-Th1 cells into $A \beta$-Th17 Teffs using selective culture media. Adoptive transfer of $A \beta-T h 17$ cells may have induced a combined Th1/Th17 Teff pathogenesis via IFN $\gamma$ and IL12 signaling [50]. In agreement with our results, clinical studies have shown increased frequency of IFNY secreting Th1 [51] and IL17-secreting Th17 cells $[14,15]$ in the early-stage AD patients compared to healthy controls. Our own and other laboratories have demonstrated neurotoxic effects of antigen-specific 


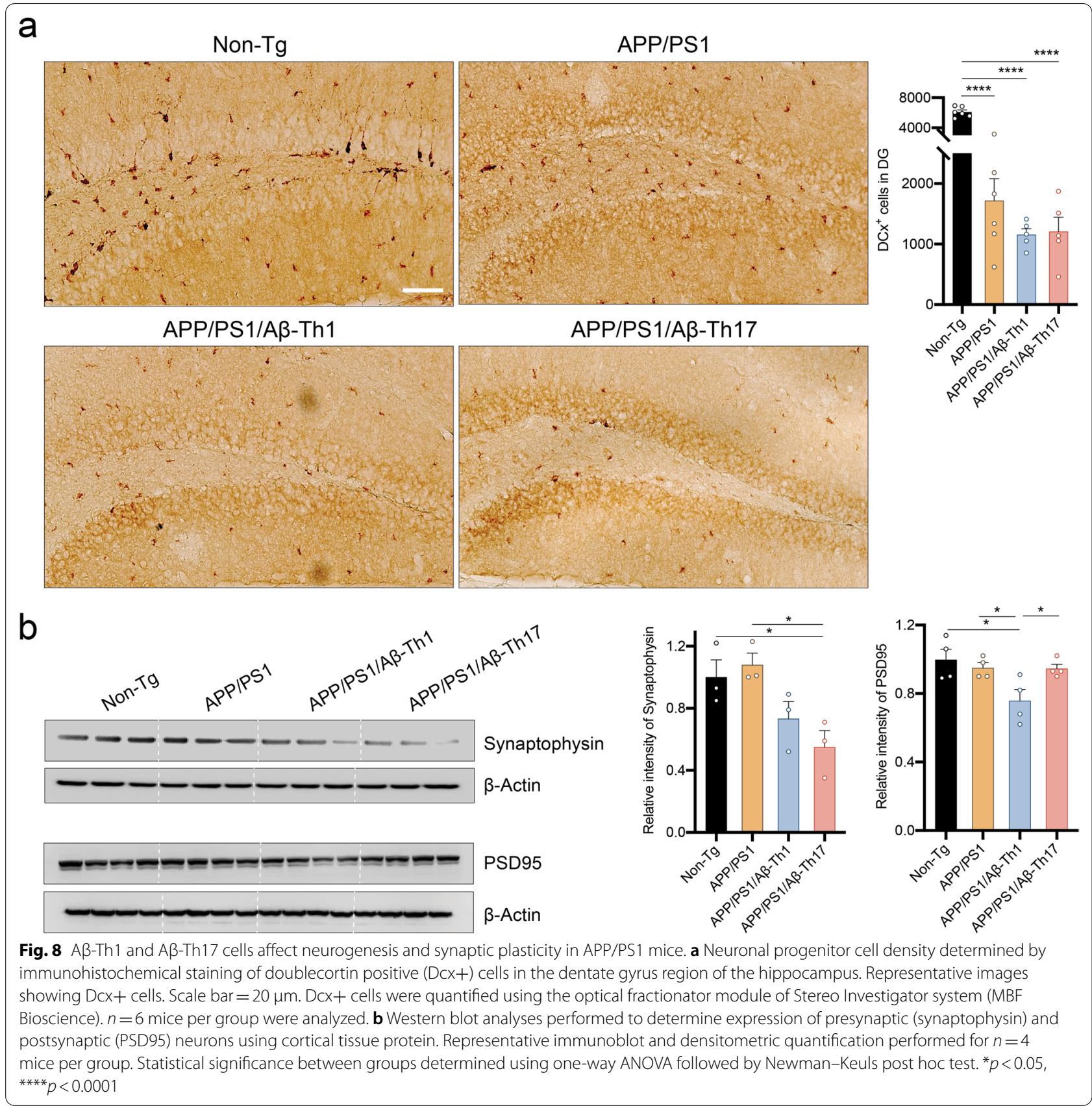

Th17 cells in PD animal models [34] and patients [39]. Indeed, peripheral adaptive immune impairments are comparable between the two most common neurodegenerative diseases, $\mathrm{AD}$ and $\mathrm{PD}[35,39,52]$, and has been speculated that disease operative Th17 cells are also deleterious, although to a lesser extent than Th1 cells in AD pathogenesis.

Systemic inflammation is operative in AD patients before the onset of memory impairment. This suggests an important role of peripheral immune activation in disease [15, 32, 33]. A $\beta$ drains to the peripheral cervical lymph nodes [53] where APCs process and present $A \beta$ peptides to peripheral $\mathrm{T}$ cells engaging MHC-I or -II, which initiates peripheral adaptive immune activation $[2,11,54]$. However, with disease progression, $A \beta$ lymphatic drainage is compromised leads to the formation of cerebral amyloid angiopathy and $A \beta$ accumulation [55]. In parallel, clonally expanded and activated peripheral $\mathrm{T}$ cells expressing chemokines (CCL3, CCL4) cross the blood-brain barrier (BBB) and affect resident microglia 
and neuronal cells perpetuating a neuroinflammatory state $[21,56]$. Recently, Gate et al. showed elevated frequency of CD8+ effector memory T cells in the blood of AD patients which negatively correlated with memory function [13]. The peripheral CD8+ Teffs invaded the CNS, clonally expanded into the cerebrospinal fluid, and contributed to neuroinflammation [13]. Here, adoptive transfer of A $\beta$-Th 1 and A $\beta$-Th17 Teffs into APP/PS1 mice increased the frequency of antigen-specific $\mathrm{T}$ cells. This was demonstrated by increased expression of TNF $\alpha$-, IFN $\gamma^{-}$and IL17-secreting and MHCII-IA ${ }^{\mathrm{b}}-\mathrm{A} \beta$ peptide tetramer reactive $\mathrm{CD} 4+\mathrm{T}$ cells. Elevated Th1 and Th17 cytokines then weaken tight junctions of the BBB to allow peripheral inflammatory mediators, including TNF $\alpha$, IL1 $\beta$, and IL6, entrance into the brain serving to further activate resident microglia. We contend that reactive microglia contribute to aberrant adaptive immune responses by presenting cognate antigen and secreting pro-inflammatory cytokines [57]. The direct involvement of $A \beta$-Teff-induced systemic inflammatory responses in the neuroinflammatory cascade and amyloid deposition is a pivotal pathogenic process for AD.

Previous studies reported decreased frequency and function of anti-inflammatory and immunosuppressive CD4+CD25+FOXP3+ Tregs in blood of AD patients $[52,58]$ and experimental animal models [6]. Additionally, transient breaking of immune tolerance by Treg depletion is associated with amyloid clearance and neuroinflammation restoration via subsequent CNS recruitment of immunoregulatory Treg and monocyte-derived macrophages [41]. Other reports demonstrated the neuroprotective potential of polyclonal Treg-adoptive transfer or expansion in AD animal models [59, 60], PD [61, 62], and ALS patients [63]. Together, these reports suggest a role of Treg deficits in AD progression, but the underlying cause is unknown. For the first time, we identified the role of disease operative $\mathrm{CD} 4+\mathrm{A} \beta$-Teff subsets in Treg dysfunction in APP/PS1 mice. We demonstrated that adoptive transfer of $A \beta-T h 1$ and $A \beta-T h 17$ cells significantly reduced the frequency of CD4+CD25+FOXP3+ Tregs in blood, spleen and lymph nodes of APP/PS1 mice. Additionally, Treg immunosuppressive function was greatly compromised in APP/PS1 mice receiving $A \beta$-Th1 cells compared to $A \beta-T h 17$ treated or untreated APP/PS1 mice. Interestingly, $A \beta$-Teffs affected Treg function in both periphery and CNS. It is speculated that antigen-specific CD4+ T cells detected after adoptive transfer elicited Treg impairments to progress $A D$ pathology in mice $[2,64]$.

Microglia serve key roles in processing and presenting self-antigens including $A \beta$ to $T$ cells to maintain immune tolerance $[2,19]$. Non-activated microglia exhibit ramified morphology and are able to clear $A \beta$ deposits through phagocytosis. However, with disease progression, microglia become more activated and acquire amoeboid morphology with compromised phagocytic capabilities [9]. Upon antigenic stimulation, microglia can acquire either classically activated (M1) or alternatively activated (M2) phenotype, representing pro-inflammatory and anti-inflammatory phenotypes, respectively $[6,9]$. Here, we identified that expression of iNOS, an M1 marker, was significantly elevated while that of arginase, an M2 marker, was reduced in the brain of APP/PS1/A $\beta$-Th1 mice, suggesting that diseaselinked CD4+ Teffs alter microglial polarization leading to worsen disease outcomes. Recently, using genomewide analysis and single-cell mass cytometry [65, 66], different microglial clusters were identified in various brain regions of humans and mice and were found to predominantly exist distinctly to the physiological and pathological conditions. However, the unique function associated with each microglia subset has not yet been identified. These reports suggest that microglia phenotypes are much more complicated and beyond simplified M1 and M2 phenotypes [67, 68]. Functional and pathway enrichment analysis revealed that Th1, Th2 and Th17, and cytokine and TLR signaling pathways are enriched in APP/PS1 mice brain following adoptive transfer of $A \beta$-Teffs further confirming the ability of $A \beta$-Teffs to perpetuate immune and neuroinflammatory responses.

In addition to affecting microglia responses, $A \beta-T h 1$ cells significantly increased amyloid deposition in both cortex and hippocampus regions of brain as demonstrated by increased soluble $A \beta_{1-40}$ and $A \beta_{1-42}$ as well as insoluble $A \beta$ plaques without affecting full-length APP production. A $\beta$-Th17 cell treatment affected amyloid load and microglial responses in APP/PS1 mice brain to a lesser extent compared to $A \beta-T h 1$ cells which might be due to their less extensive inflammatory responses as those induced by $A \beta-T h 1$ cells in an amyloid-rich environment. The results were further supported by the previous study showing Th1 biased immune responses accountable for most of the CD4+ Teffs' detrimental effects in APP/PS1 mice [18]. Neuroinflammation arose either as a result of Teff-driven microglia responses or through direct cytokine release $[2,11]$ affecting synaptic integrity and neurogenesis. These are both hallmarks of neurodegeneration [6,9]. Functional co-localization of pre- and post-synaptic neurons is essential for memory development, whereby defects in either neuron can worsen memory function $[9,47]$. Adoptive transfer of $A \beta-T h 1$ and $A \beta-T h 17$ cells showed significantly defective post-synaptic protein expression in APP/PS1 mice. Neuronal progenitor development is affected in the dentate gyrus region of APP/PS1 mice, which was further 
worsened by $A \beta$-Teffs, suggesting $A \beta$-Teffs impose a detrimental role in neurogenesis.

A previous study demonstrated that complete loss of peripheral adaptive immune system exacerbated amyloid deposition and neuroinflammation in 5XFAD-Rag mice and that reconstitution of this cell population restores AD pathology [7]. Likewise, from HIV infected individuals, $50 \%$ of patients develop AD-linked memory deficits later in life despite antiretroviral therapy, in part due to selective functional decline of peripheral CD4+ T cells [69]. Although, adaptive immune $\mathrm{T}$ cells are essential to control AD pathology, $\mathrm{A} \beta$-reactive Teffs can develop meningoencephalitis as evidenced in a Phase IIa clinical trial (NCT00021723) with full-length $A \beta$ immunization in QS21 adjuvant [48, 49]. Indeed, considering studies of the CNS effects of A $\beta$-Teffs in AD patients and animal models $[19,49]$, ours is the first study characterizing effects of stable, long-lived $A \beta$-Th 1 and $A \beta-T h 17$ Teff clones on neuroinflammation in the AD mouse model. We identified that $A \beta$-Th1 cells induced consistent pro-inflammatory responses in both periphery and CNS leading to memory impairment, increased amyloid load, microgliosis, and impaired neurogenesis. Tregs were identified as a key regulator of $A \beta$-Teff-driven neuroinflammation in amyloid-rich environment leading to the breakdown of immune tolerance $[2,41]$. Thus, we postulate that development of $A \beta$-specific Tregs, instead of polyclonal Tregs associated with the risk of global immunosuppression [70] might better serve as a safe and potential therapeutic alternate for management of elderly AD patients.

\section{Conclusions}

Disease-reactive $A \beta-T h 1$ and $A \beta$-Th17 cells transform a pro-inflammatory microenvironment to accelerate $\mathrm{AD}$ pathology in APP/PS1 mice. The detrimental effects of $\mathrm{A} \beta$-Teffs are sped by limiting Treg activities in the periphery and CNS. Control of this neurodestructive environment represents a potential therapeutic strategy and can be sped by augmenting peripheral Treg numbers and function reactive against disease-specific protein.

\section{Methods}

\section{Development of $A \beta$-Th 1 and $A \beta$-Th 17 cells}

Six-month-old, two female B6;129 mice were immunized by subcutaneous injection with human $A \beta_{1-42}(50 \mu \mathrm{g})$ (Catalog no. 03-112, Life Technologies) emulsified in complete Freund's adjuvant (Sigma Aldrich) containing Mycobacterium tuberculosis $(1 \mathrm{mg} / \mathrm{ml})$. The mice were boosted after 2 weeks with $A \beta_{1-42}(50 \mu \mathrm{g})$ in incomplete Freund's adjuvant (Sigma Aldrich). One week after the second immunization, the mice were killed, and spleen and lymph nodes (axial, brachial, cervical, and inguinal) were harvested then mashed through 70- $\mu \mathrm{m}$ cell strainer to prepare single cell suspensions. The red blood cells were lysed with ammonium-chloride-potassium (ACK) lysis buffer (Catalog no. A10492, Thermo Fisher Scientific). CD4+ $\mathrm{T}$ cells were enriched from single cell suspensions using an EasySep ${ }^{\mathrm{TM}}$ mouse CD4+ T cell isolation kit (Catalog No. 19852, Stemcell Technologies) and recovered CD4+ T cells (98\% CD4+ by flow cytometric analysis) were cultured in vitro in the presence of monomeric $A \beta_{1-42}(25 \mu \mathrm{g} / \mathrm{ml})$ prepared as described before [71] (Catalog no. RP10017, GenScript) and $2.5 \times 10^{7}$ feeder cells, i.e., splenocytes isolated from naïve female B6;129 mice and irradiated at 3200 Gy (RS 2000 Irradiator, Rad Source, Buford, GA). Cells were propagated in RPMI-1640 media supplemented with $10 \%$ fetal bovine serum (FBS), $2 \mathrm{mM}$ L-glutamine, $25 \mathrm{mM}$ HEPES, $1 \mathrm{mM}$ sodium pyruvate, $1 \times$ nonessential amino acids, $55 \mathrm{nM}$ 2-mercaptoethanol, $100 \mathrm{U} / \mathrm{ml}$ penicillin, and $100 \mu \mathrm{g}$ streptomycin. Fresh culture media, $A \beta$, and feeder cells were provided weekly and the viable CD4+ T cells were counted before each passage. $\mathrm{CD} 4+\mathrm{T}$ cells non-reactive to $A \beta$ were eliminated over passages as evidenced by declined viable CD4+ cell count up to day 21 (Additional file 1: Fig. S1a). On day 28, increased $A \beta$-reactive $\mathrm{CD} 4+\mathrm{T}$ cell count was observed and at this point $25 \mathrm{U} /$ $\mathrm{ml}$ interleukin-2 (IL2) was added to the culture, leading to further increase in $\mathrm{A} \beta$-reactive $\mathrm{CD} 4+$ count thereafter. To recover $\mathrm{CD} 4+\mathrm{T}$ cell clones, cells were cultured at $1 \mathrm{cell} /$ well in flat-bottom 96-well plate in presence of fresh feeder cells and $A \beta_{1-42}$. The most rapidly growing $A \beta$-reactive clone was identified and propagated with IL2, $A \beta_{1-42}$, and feeder cells, and hereafter is designated as $A \beta-T h 1$ cells. $A$ subclone of $A \beta-T h 1$ was polarized to Th17-type Teffs by culturing in complete RPMI media supplemented with $3 \mathrm{ng} / \mathrm{ml}$ TGF $\beta, 25 \mathrm{ng} / \mathrm{ml} \mathrm{IL6,} 5 \mathrm{ng} /$ $\mathrm{ml}$ IL1 $\beta, 20 \mathrm{ng} / \mathrm{ml} \mathrm{IL23} \mathrm{and} 3 \mu \mathrm{g} / \mathrm{ml}$ of antibodies to IL4, IFN $\gamma$, and IL2 in the presence of $A \beta_{1-42}$ and fresh feeder cells; hereafter designated as $\mathrm{A} \beta-\mathrm{Th} 17$ cells.

\section{Cell phenotypes and antigen-specificities}

To induce cytokine production, $10^{6} \mathrm{~A} \beta$-Th 1 or $\mathrm{A} \beta$-Th 17 cells were stimulated in complete RPMI-1640 media containing $20 \mathrm{ng} / \mathrm{ml}$ PMA, $1 \mu \mathrm{M}$ ionomycin (Sigma Aldrich), and $3 \mu \mathrm{g} / \mathrm{ml}$ brefeldin A (Catalog no. 4506521, eBioscience) for $12 \mathrm{~h}$, then extracellular/intracellular staining was performed for flow cytometric analysis as described before $[6,72]$. Cells were first stained for surface biomarker expression with anti-CD3e-PE (Catalog no. 12003181, eBioscience), anti-CD4-APC-H7 (Catalog no. 560181, BD Pharmingen), and anti-CD8aPE-Cyanine 5.5 (Catalog no. 35008180, eBioscience) antibodies for $30 \mathrm{~min}$ at room temperature. For intracellular staining, cells were fixed and permeabilized 
using transcription factor staining buffer kit (Cata$\log$ no. 552300, eBioscience) for $45 \mathrm{~min}$ at $4{ }^{\circ} \mathrm{C}$, followed by incubation with anti-IFN $\gamma$-FITC (Catalog no. 11731182, eBioscience), anti-TNFo-eFluor 450 (Catalog no. 48732182, eBioscience), anti-IL17a-Alexa Fluor 647 (Catalog no. 506912, BioLegend), anti-Tbet-eFluor 660 (Catalog no. 50582582, eBioscience) and anti-RORYPerCp eFluor 710 antibodies (Catalog no. 46698182, eBioscience) for $30 \mathrm{~min}$ at $4{ }^{\circ} \mathrm{C}$. Isotype and fluorescence-minus-one (FMO) controls for each antibody were used during flow cytometric analysis for accurate gating of different cell subsets. For analysis of extracellular cytokine release, $A \beta-T h 1$ and $A \beta-T h 17$ cells were stimulated with $20 \mathrm{ng} / \mathrm{ml}$ PMA and $1 \mu \mathrm{M}$ ionomycin for $12 \mathrm{~h}$ and culture supernatants were analyzed using proteome profiler mouse cytokine array kit (Catalog no. ARY006, R\&D Systems) according to the manufacturer's instructions. $\mathrm{CD} 3+\mathrm{CD} 4+\mathrm{T}$ cells were gated to quantify the intracellular cytokine and transcription factor expression. Few endogenous feeder cells were present during extracellular immunoblot staining that might have affected the cellular cytokine signature during short activation period.

From $A \beta_{1-42}$ sequence, 1 to 15 amino acid region (DAEFRHDSGYEVHHQ) comprises B cell epitope while 15 to 30 amino acid region (KLVFFAEDVGSNKGA) comprises $\mathrm{T}$ cell epitope in the mice while in human it may be up to 15 to 42 amino acid region [51]. To elucidate the ability of $A \beta-T h 1$ and $A \beta-T h 17$ cells to recognize the $T$ cell epitope of $A \beta_{1-42}$ presented by $\mathrm{H}-2^{\mathrm{b}}$ haplotypes (feeder cell matched), tetramers were constructed with $\mathrm{I}-\mathrm{A}^{\mathrm{b}}$ and the amino acid 15-30 (MHCII-IA ${ }^{\mathrm{b}}$-KLVFFAEDVGSNKGA) conjugated to fluorophore BV421 (National Institute of Health (NIH) Tetramer Core Facility, Emory University, Atlanta, GA). MHCII-IA ${ }^{\text {b }}$-PVSKMRMATPLLMQA tetramer with no $A \beta$ specificity was used as control. For tetramer staining, $3 \times 10^{5} \mathrm{~A} \beta$-Th 1 or $\mathrm{A} \beta$-Th17 cells were incubated with increased concentrations of MHCII-IA ${ }^{\mathrm{b}}-\mathrm{KLVF}$ FAEDVGSNKGA A $\beta$ tetramer $(1.2 \mu \mathrm{g}, 2.4 \mu \mathrm{g}$ and $12 \mu \mathrm{g})$ or MHCII-IA ${ }^{\mathrm{b}}$-PVSKMRMATPLLMQA control tetramer $(2.4 \mu \mathrm{g})$ for $3 \mathrm{~h}$ at $37^{\circ} \mathrm{C}$. After incubation, tetramer-stained $\mathrm{T}$ cells were reacted with anti-CD3e$\mathrm{PE}$ and anti-CD4-APC-H7 antibodies for $30 \mathrm{~min}$ at room temperature, followed by live-dead staining with propidium iodide $(0.5 \mu \mathrm{g} / \mathrm{ml})$ for $5 \mathrm{~min}$ at room temperature. Stained T cells were analyzed with a LSR II flow cytometer and FACSDiva Software (BD Bioscience) at the University of Nebraska Medical Center Flow Cytometry Research Facility.

\section{T cell receptor identification}

Total RNA was isolated from the parent $\mathrm{T}$ cell clone $(\mathrm{A} \beta$ Th1 cells) using RNAeasy mini kit (Catalog no. 74104, Qiagen). First strand complementary DNA (cDNA) was synthesized and TCR $\alpha$ and TCR $\beta$ chain variable region sequences were amplified using SMARTer ${ }^{\circledR}$ mouse TCR a/b profiling kit (Catalog no. 634402, Takara). For the TCR sequence identification, PCR products generated were cloned into the $\mathrm{pCR}^{\mathrm{TM}} 4 \mathrm{Blunt}-\mathrm{TOPO}{ }^{\circledR}$ plasmid using Transform One Shot ${ }^{\circledR}$ Mach-T1 ${ }^{\mathrm{TM}}$ competent cells following manufacturer's instructions (Catalog no. 450031, Life Technologies). Bacterial colonies were grown in LB agar media followed by DNA isolation and clean-up using monarch plasmid miniprep kit (Catalog no. T1010S, New England BioLabs) and samples were submitted for Sanger sequencing with M13 primers at the University of Nebraska Medical Center Genomics Core Facility.

\section{Modeling of TCR-pMHC complex}

The TCR-A $\beta-$ MHCII (TCR-pMHC) complex was constructed with the fully automated structure preparation and homology modeling in the Schrodinger BioLuminate suite [73]. The loops were modeled using ab initio loop modeling and cross validated on the SwissModel server $[74,75]$. The quality estimation of the generated model and subsequent refinements were performed by MolProbity and QMEAN method on SwissModel [76]. The full query sequence was used for the modeling studies, MHC consisted of two chains: MHCII-IA ${ }^{\mathrm{b}} \alpha$ with 256 residues (1-256) and MHCII-IA ${ }^{\mathrm{b}} \beta$ with 264 residues (257-521). A $\beta$ peptide had 42 residues (522-563), TCR $\alpha$ consisted of 274 residues (564-838) and TCR $\beta$ consisted of 305 residues (839-1144). The MHC-peptide residues were first modeled with the antibody modeling tools prediction and advanced homology modeling. The TCR $\alpha / \beta$ complex was modeled later and both models were analyzed separately for structural features. The single model was generated from the above-mentioned tools, the structural features were validated from the previously generated models. System preparation: All molecular dynamics (MD) simulations were performed on AMBER 18 software package [77]. The protein complex was prepared with the help of XLeap [78]. The TCR-pMHC complex was solvated in a truncated octahedron box unit of dimensions $x=192.98, y=186.34$ and $z=182.65$. Total of 125,812 TIP3P water molecules were added to solvate the system [79]. A sufficient number of counter ions, $\mathrm{Na}+$ and $\mathrm{Cl}-$, were added to neutralize the simulation system and achieve $0.14 \mathrm{M}$ of ionic strength. FF14SB force field was used to parameterize the amino acids and to model the proteins [80]. Unbiased explicit solvent MD simulation: Simulations were performed for $100 \mathrm{~ns}$ of time step on Nvidia V100-SXM2-16 GB Graphic Processing 
Unit using the PMEMD.CUDA module [81]. Simulations were run at $1 \mathrm{~atm}$ constant pressure using Monte Carlo barostat and $300 \mathrm{~K}$ constant temperature by using Langevin thermostat with a collision frequency of 2 ps-1 and the volume exchange was attempted for every $100 \mathrm{fs}$. An integration step of 2 fs was also used for simulation of hydrogen atoms involving bonds were constrained by using SHAKE algorithm [82]. Long-range electrostatic interactions were computed using Particle Mesh Ewald method while for short-range interaction a cutoff of $8 \AA$ was used [83]. Equilibration consisted of rounds of NVT and NPT equilibration for $10 \mathrm{~ns}$ in total. CPPTRAJ [84] was used to analyze the interactions over full trajectory after taking configuration at every 4 ps. RMSD, RMSF was determined after analyzing the trajectories.

\section{Adoptive transfer in APP/PS1 mice}

All animal experiments were approved by the institutional Animal Care and Use Committee of University of Nebraska Medical Center. Transgenic mice overexpressing human APP695 with the Swedish mutation (Tg2576) were obtained from Drs. G. Carlson and K. Hsiao-Ashe through the Mayo Medical Venture [85]. PS1 mice overexpressing human PS1 with M146L mutation were provided by Dr. K. Duff through the University of South Florida [86]. Both mice were maintained on the B6;129 hybrid background. Male Tg2576 mice were crossbred with female PS1 mice to generate APP/PS1 double-transgenic mice and non-transgenic (non-Tg) B6;129 mice were developed in parallel as described previously $[6,9$, 87, 88]. Female APP/PS1 mice, $4-5$ months old, and agematched non- $\mathrm{Tg}$ littermates were randomly divided into the different experimental groups. Either $1 \times 10^{6} \mathrm{~A} \beta$-Th1 or $\mathrm{A} \beta$-Th17 cells in $100 \mu \mathrm{l}$ phosphate-buffered saline (PBS) were adoptively transferred to the APP/PS1 recipient mice, intravenously via tail vein using a 28 -gauge needle affixed to a sterile tuberculin syringe, twice at 1-week intervals. Untreated and age-matched non-Tg mice served as control.

\section{Radial arm water maze test}

Two weeks after the second adoptive cell transfer, mice were submitted for radial arm water maze (RAWM) testing in a blinded fashion to assess memory impairment as previously described $[6,71]$. Briefly, mice from masked cages were introduced into the circular water filled tank (diameter-110 cm and height-91 cm, San Diego Instruments) with triangular inserts that produce six swim paths radiating from the center. Special cues are fixed on the tank wall to guide mouse orientation. At the end of any one arm, a circular Plexiglass hidden platform (diameter $-10 \mathrm{~cm}$ ) is placed submerged $1 \mathrm{~cm}$ beneath the water level. The platform was placed in the same arm for four consecutive acquisition trials (T1-T4), and retention trial (T5), but in a different arm on different experimental days. For T1-T4, the mouse started the task from a randomly chosen arm without a platform. After four trials, the mouse was returned to its cage for $30 \mathrm{~min}$ and reintroduced into the $\mathrm{T} 4 \mathrm{arm}$, for the delayed retention trial (T5). Each trial lasted $1 \mathrm{~min}$, and an error was scored when mouse entered the wrong arm; entered the arm with the platform, but did not climb on it; or did not make a choice for $20 \mathrm{~s}$. The trial ended when the mouse climbed and stay on the platform for at least $10 \mathrm{~s}$. The mouse allowed to rest on the platform for $20 \mathrm{~s}$ between trials. If the mouse did not climb the platform, after $60 \mathrm{~s}$ it was gently guided to the submerged platform. The T1, T4 and T5 trial errors over 9-day test were divided into three blocks (block-1 days 1-3, block-2 days 4-6, block-3 days 7-9), and the errors in each block were averaged for statistical analysis.

\section{2-Deoxy glucose chemical exchange saturation transfer (glucoCEST) MRI}

Mice were fasted for $24 \mathrm{~h}$ and fasting blood glucose concentrations were measured prior to the experiment using glucometer and test strips (ReliOn ${ }^{\mathrm{TM}}$ Prime) by collecting blood from tail vein puncture. Mice were anesthetized with isoflurane in the mixture of oxygen and the peritoneal cavity was cannulated for the injection of 2-deoxy glucose (2DG). Cannulated mice were fixed on a ${ }^{1} \mathrm{H}$ magnetic resonance imaging (MRI)-compatible cradle using a bite bar. MRI was performed on a 7-Tesla scanner (Bruker PharmaScan, Billerica, MA) with a Bruker-built quadrature mouse brain RF coil. Respiration and body temperature were monitored during scanning. A baseline glucose CEST (glucoCEST) MRI was acquired followed by 2DG $(1 \mathrm{~g} / \mathrm{kg}$ in PBS) injection via intraperitoneal catheter into the mice to monitor glucose signal in the brain over the time. GlucoCEST data were acquired using a rapid acquisition with relaxation enhancement (RARE) sequence (repetition time (TR)/echo time (TE) $=1600 / 16 \mathrm{~ms}$, RARE factor $=8$ ) with a continuous radio frequency $(\mathrm{RF})$ for saturation with the power $=3 \mu \mathrm{T}$, duration $=1 \mathrm{~s}$, saturation frequencies $=-1600$ to $1600 \mathrm{~Hz}$ in steps of $80 \mathrm{~Hz}$. A second CEST data with saturation RF power $=0.5 \mu \mathrm{T}$, and frequencies $=-300$ to $+300 \mathrm{~Hz}$ were acquired for B0 inhomogeneity correction using WASSR [89]. The glucoCEST scan time was $\sim 10 \mathrm{~min}$, and was repeated at $10,20,30,40,50$, and 60 min after 2DG injection. Asymmetric magnetization transfer ratio (MTRasym) was calculated from the Z-spectrum that was built based on CEST data. The glucoCEST signal was calculated as the integral of the MTRasym within $1.00 \pm 0.25$ p.p.m. 


\section{Flow cytometry}

On day 42, mice were terminally anesthetized with pentobarbital followed by spleen isolation in complete RPMI media and blood collection via cardiac puncture in the K3EDTA tubes (Catalog no. 450475, Greiner BioOne North America). Lastly, mice were pericardially perfused with PBS and lymph nodes (axial, brachial, cervical, and inguinal) and brain were harvested. Whole blood was stained while single cell suspension was prepared from spleen and lymph nodes. Either $50 \mu \mathrm{l}$ of blood or $1 \times 10^{6}$ spleen or lymph node cells were stained for flow cytometric analysis as described above using antibodies: anti-CD3e-PE, anti-CD4-APC-H7, anti-CD8a-PECyanine 5.5, anti-CD25-PE-Cy7 (Catalog no. 25025182, eBioscience), anti-Tbet-eFluor 660, anti-ROR $\gamma$-PerCp eFluor 710 and anti-FOXP3-Alexa Fluor 488 (Catalog no. 320012, BioLegend). For intracellular cytokine analysis, $1 \times 10^{6}$ spleen cells were stimulated with $20 \mathrm{ng} / \mathrm{ml}$ PMA and $1 \mu \mathrm{M}$ ionomycin in presence of brefeldin A for $12 \mathrm{~h}$ and after incubation cells were stained with anti-CD3ePE, anti-CD4-APC-H7, anti-IFN $\gamma$-FITC, anti-TNFoeFluor 450, and anti-IL17a-Alexa Fluor 647 antibodies. To determine the frequency of $A \beta$ reactive $C D 4+T$ cells, $1 \times 10^{6}$ lymph node cells were stimulated with $\mathrm{A} \beta_{1-42}$ $(25 \mu \mathrm{g} / \mathrm{ml})$ in presence of feeder cells and IL2 $(25 \mathrm{U} /$ $\mathrm{ml}$ ) for 5 days at $37^{\circ} \mathrm{C}$. On day 5 , cells were collected by centrifugation and incubated with MHCII-IA ${ }^{\mathrm{b}}-\mathrm{KLVF}-$ FAEDVGSNKGA A $\beta$ tetramer $(6 \mu \mathrm{g})$ or MHCII-IA $^{\mathrm{b}}-$ PVSKMRMATPLLMQA control tetramer $(6 \mu \mathrm{g})$ for $3 \mathrm{~h}$ at $37{ }^{\circ} \mathrm{C}$. After incubation, $\mathrm{T}$ cell-MHCII-A $\beta$ tetramer complex was stained with anti-CD3e-PE, anti-CD4-APC$\mathrm{H} 7$ antibodies and propidium iodide for flow cytometric analysis.

\section{Treg function assay}

CD4+CD25+ Tregs and CD4+CD25- T responder cells (Tresps) were isolated from the mice spleen as described earlier [72] using EasySep ${ }^{\mathrm{TM}}$ mouse Treg enrichment kit (Catalog no. 18783, Stemcell Technologies) as per the manufacturer's instructions. Briefly, CD4+ T cells from single cell suspensions were first enriched by negative selection using the EasySep ${ }^{\mathrm{TM}}$ mouse CD4+ T cell isolation cocktail from which CD25+ cells were then positively selected using EasySep ${ }^{\text {TM }}$ mouse CD25+ Treg selection cocktail. The isolated CD4+CD25+ cells were more than 97\% FOXP3+ as determined by flow cytometric analysis. CD4+CD25- Tresps, more than 96\% pure, were collected from naïve non-Tg mice spleens and used in the proliferation assay after labeling with carboxyfluorescein succinimidyl ester (CFSE) (Catalog no. C34554, Thermo Fisher Scientific). CD4+CD25+ Tregs from different experimental groups were serially diluted in U-bottom 96-well plate to obtain 50, 25, 12.5, and
$6.25 \times 10^{3}$ Tregs in $100 \mu \mathrm{l}$ of media followed by addition of $50 \times 10^{3}$ CFSE-labeled Tresps into each well to obtain Tresp:Treg rations of 1:1, 1:0.5, 1:0.25 and 1:0.125, while wells with only Tresps served as controls. Mouse $\mathrm{T}$ cell activating CD3/CD28 Dynabeads (Catalog no. 11456D, Thermo Fisher Scientific) were added to each well at a bead:Tresp ration of 1:1 to induce Tresp proliferation. The immunosuppressive function of Tregs to inhibit proliferation of CFSE-stained Tresps was determined after $72 \mathrm{~h}$ incubation at $37^{\circ} \mathrm{C}$ using flow cytometric analysis and is reported as Treg-mediated \% inhibition.

\section{Transcriptomic and functional and pathway enrichment analysis}

Hippocampal tissue was isolated from mouse brain and total RNA extracted with the RNAeasy mini kit (Catalog no. 74104, Qiagen). Recovered RNA was reverse transcribed into cDNA using a RevertAid First Strand cDNA Synthesis kit (Catalog no. K1622, Thermo Fisher Scientific). One microgram cDNA was amplified using primer mix from the $\mathrm{RT}^{2}$-PCR array for Mouse Innate and Adaptive Immune Responses (Catalog no. 330231, Qiagen). Quantitative RT-PCR was performed using Mastercycler Realplex EP (Eppendorf) and data were analyzed using $\mathrm{RT}^{2}$ Profiler PCR array web-based data analysis software (Qiagen). Next, we conducted functional and pathway enrichment analysis of genes deregulated in APP/PS1 mice untreated or treated with A $\beta$-Teffs compared to non-Tg and APP/PS1 control mice. GSEA is a method to identify classes of genes or proteins that over-represented in a large set of genes or proteins [90]. We conducted GSEA analysis to assess the enrichment of annotated gene sets in KEGG, Reactome and STRING local network clusters. KEGG pathway enrichment analysis was conducted using DAVID (http://david.abcc.ncfcrf.gov/) [91], which is an online tool providing a comprehensive set of functional annotations to understand biological meaning behind large list of genes. Reactome GSEA analysis was conducted using ReactomeFIViz (https://reactome.org/tools/react ome-fiviz) [92], which is a cytoscape app for pathway and network-based data analysis. STRING local network cluster enrichment analysis was conducted using STRING (http://string-db.org). KEGG is a database regarding genomes, biological pathways, diseases, drugs and chemical substances (http://www.genome/ ad.jp/kegg) [93]. Reactome (http://www.reactome.org) is an open source, expert-authored, peer-reviewed, manually curated database of reactions, pathways and biological processes. STRING (http://string-db.org) database provides a critical assessment and integration of protein-protein interaction (PPI), including direct 
(physical) and indirect (functional) associations in a given organism [94].

\section{Immunohistochemistry}

After transcardial perfusion, mouse brains were immediately harvested and divided into two hemispheres. The left was immediately frozen on dry ice for biochemical analysis and right was immersed in freshly depolymerized $4 \%$ paraformaldehyde in PBS for $48 \mathrm{~h}$ at $4{ }^{\circ} \mathrm{C}$ and cryoprotected by immersion in $15 \%$ then $30 \%$ sucrose for $24 \mathrm{~h}$ at $4{ }^{\circ} \mathrm{C}$. Fixed brains were sectioned coronally with a Cryostat (ThermoFisher) with $30-\mu \mathrm{m}$-thick sections serially collected and stored at $-80{ }^{\circ} \mathrm{C}$. Immunohistochemistry was performed using antibodies against pan-A $\beta$ (1:500, rabbit polyclonal, Catalog no. 715800, Thermo Fisher Scientific), Iba1 (1:1000, rabbit polyclonal, Catalog no. 01919741, Wako) and doublecortin (Dcx) (1:500, goat polyclonal, Catalog no. Sc8066, Santa Cruz Biotechnology). For immunodetection, biotin-conjugated anti-rabbit or anti-goat IgG secondary antibody was used followed by a tertiary incubation with Vectastain $A B C$ Elite kit (Catalog no. PK6100, Vector Laboratories). 1\% Thioflavin-S in 50\% ethanol was used for counterstaining of compact amyloid plaque (Catalog no. T1892, Sigma). For each of the immunohistochemical staining, six sections/slide were collected at eight intervals and were used for each of the experimental groups. Slides were masked and coded and $A \beta$ occupied area was calculated using Cavalieri estimator probe (grid spacing $15 \mu \mathrm{m})$, while the number of Iba1-reactive microglia and Dcx-positive $(\mathrm{Dcx}+)$ neuroprogenitor cells were counted using the optical fractionator module of Stereo Investigator system (MBF Bioscience) as described earlier [9]. Briefly, a high-sensitivity digital camera (OrcaFlash2.8, Hamamatsu C11440-10C, Hamamatsu, Japan) interfaced with a Nikon Eclipse 90i microscope (Nikon, Melville, NY, USA) was used. Within the Stereo Investigator program, the contour in each section was delineated using a tracing function. While sections showed tissue shrinkage along the anteroposterior axis, the extent of shrinkage between different animals was considered similar. The dimensions for the counting frame $(120 \times 100 \mu \mathrm{m})$ and the grid size $(245 \times 240 \mu \mathrm{m})$ were set. The z-plane focus was adjusted at each section for clarity. Cells were quantified by the fractionator with marked positive cells in each counting frame. Based on the set parameters and marked cell counts, Stereo Investigator computed cell population estimates for comparison between groups.

\section{Western blot analysis}

Brain cortical tissues were homogenized using lysis buffer containing $50 \mathrm{mM}$ Tris- $\mathrm{HCl}(\mathrm{pH} 8.0), 150 \mathrm{mM}$ $\mathrm{NaCl}, 50 \mathrm{mM}$ EDTA, $1 \%$ Triton X-100, and a mixture of protease/phosphatase inhibitor (Catalog no. 89901, Thermo Fisher Scientific). The lysate was centrifuged at $20,000 \times g$ for $20 \mathrm{~min}$ at $4{ }^{\circ} \mathrm{C}$, the supernatant collected and total protein quantified using micro-BCA kit (Cata$\log$ no. 23235, Thermo Fisher Scientific). For Western blots, $80 \mu \mathrm{g}$ or $20 \mu \mathrm{g}$ of tissue protein was incubated with $\beta$-mercaptoethanol containing Laemmli buffer at $100{ }^{\circ} \mathrm{C}$ for $5 \mathrm{~min}$, followed by electrophoresis on SDS-polyacrylamide gel and transferred to polyvinylidene fluoride membrane (Immobilon-P, Catalog no. IPVH00010, Millipore). The membranes were blocked in 5\% skim milk/ TBST and incubated with primary antibodies to $22 \mathrm{C} 11$ (1:2000, Catalog no. MAB348, Millipore Sigma), 6E10 (1:2000, Catalog no. 803001, BioLegend), arginase 1 (1:300, Catalog no. 93668S, Cell Signaling Technology), iNOS (1:300, Catalog no. 13120S, Cell Signaling Technology), synaptophysin (1:1000, Catalog no. MAB5258, Millipore), PSD95 (1:1000, Catalog no. ab18258, Abcam) and $\beta$-actin (1:2000, Catalog no. A3854, Sigma) at $4{ }^{\circ} \mathrm{C}$ overnight, followed by $60 \mathrm{~min}$ incubation in $5 \%$ skim milk/TBST with horseradish peroxidase-conjugated anti-rabbit, mouse, or goat secondary antibodies (1:2000, Santa Cruz Biotechnology). Immunoreactive bands were detected using SuperSignal West Pico or Femto Chemiluminescent substrate, and images were captured using an iBlot750 Imager (Thermo Fisher Scientific). Immunoblots were quantified using ImageJ software $(\mathrm{NIH})$ relative to $\beta$-actin expression.

\section{$A \beta$ detection by ELISA}

Mouse cortical tissues were homogenized in $50 \mathrm{mM}$ Tris- $\mathrm{HCl}(\mathrm{pH}$ 7.6) containing $150 \mathrm{mM} \mathrm{NaCl}$ and a protease/phosphatase inhibitor mixture. The homogenate was centrifuged at $20,000 \times g$ for $20 \mathrm{~min}$ at $4{ }^{\circ} \mathrm{C}$ and the supernatant was analyzed for human $A \beta_{1-40}$ and $A \beta_{1-42}$ by ELISA (Catalog nos. KHB3482 and KHB3442, Thermo Fisher Scientific) according to the manufacturer's instructions.

\section{Statistical analysis}

All data were normally distributed and presented as mean values \pm standard errors of the mean (SEM). Comparisons of means between groups were analyzed by one-way ANOVA or two-way repeated measures ANOVA followed by Newman-Keuls post hoc test using GraphPad Prizm software version 8.0 (GraphPad Software, San Diego, CA). A value of $p \leq 0.05$ was regarded as a significant difference. 


\begin{abstract}
Abbreviations
AB: Amyloid beta; ACK: Ammonium-chloride-potassium; AD: Alzheimer's disease; APP: Amyloid precursor protein; APCs: Antigen presenting cells; AUC: Area under curve; BBB: Blood-brain barrier; CDNA: Complementary DNA; CEST: Chemical exchange saturation transfer; CFSE: Carboxyfluorescein succinimidyl ester; CNS: Central nervous system; Dcx: Doublecortin; 2DG: 2-Deoxy glucose; 2DG6P: 2DG-6-phosphate; FBS: Fetal bovine serum; ${ }^{18} \mathrm{~F}-\mathrm{FDG}:{ }^{18} \mathrm{~F}$-radiolabeled fluorodeoxyglucose; FMO: Fluorescence-minus-one; FOXP3: Forkhead box P3; GSEA: Gene set enrichment analysis; IFNy: Interferon gamma; IL2: Interleukin-2; IL17: Interleukin 17; iNOS: Inducible nitric oxide synthase; KEGG: Kyoto Encyclopedia of Genes and Gnomes; MD: Molecular dynamics; MHCII: Major histocompatibility complex II; NF-kB: Nuclear factor-kappa B; PBS: Phosphatebuffered saline; PET: Positron emission tomography; PMHC: Peptide-MHCIl; PPI: Protein-protein interaction; PS1: Presenilin 1; RAWM: Radial arm water maze; RMSD: Root-mean-square deviation; RMSF: Root-mean-square fluctuations; RORY: RAR-related orphan receptor gamma; SEM: Standard errors of the mean; STRING: Search Tool for the Retrieval of Interacting Genes/Proteins; Tbet: T-box expressed in T cells; TCR: T cell receptor; Teff: Effector T cell; Th1: Type 1 Thelper; Th2: Type 2 Th; Th17:Type 17 Th; TIR:Toll/IL1 receptor; TNFa: Tumor necrosis factor alpha; Treg: Regulatory T cell; Tresp: T responder cell.
\end{abstract}

\section{Supplementary Information}

The online version contains supplementary material available at https://doi. org/10.1186/s12974-021-02308-7.

Additional file 1: Figure S1. Development of monoclonal A $\beta$-Th1 and $A \beta$-Th17 cells. Figure S2. Modelling and explicit solvent molecular dynamics simulations. Figure $\mathbf{S} \mathbf{3}$. Adoptive transfer of A $\beta$-Teffs did not affect T cell frequency in APP/PS1 mice. Figure S4. Transcriptomic analysis of immune genes. Figure $\mathbf{S 5}$. Western blot images.

\section{Acknowledgements}

The authors thank the Flow Cytometry Research Core Facility at the University of Nebraska Medical Center for assistance with flow cytometric analyses. The authors also thank National Institutes of Health tetramer core facility at Emory University for preparing our tetramer design. RC acknowledges the Computational Shared Facility 3 (CSF3) at University of Manchester, UK.

\section{Authors' contributions}

$J M, R L M, H E G$ conceived and planned experiments; JM, PY, YL performed animal experiments, JM, EF performed behavioral experiments; RC performed molecular modeling; KLN processed animal tissue samples; JM, MM, L performed transcriptomics analysis; JM, BDK prepared figures; YL performed MRl; $J H, K E O, J G, R M Q$ provided technical support and edited manuscript; $T K, X W$, LYP, CBG oversight research progress, provided constructive suggestions and edited manuscript; JM, RLM, HEG wrote the manuscript. The authors edited the final manuscript. All authors read and approved the final manuscript.

\section{Funding}

This work was supported by the National Institutes of Health Grants P01 DA028555, R01 NS36126, P01 NS31492, P01 MH64570, P01 NS43985, P30 MH062261, R01 AG043540, and 2R01 NS034239; the Frances and Louie Blumkin and Harriet Singer Research Foundations, the Carol Swarts, MD Emerging Neuroscience Research Laboratory; and the Margaret R. Larson Professorship.

\section{Availability of data and materials}

The datasets supporting the conclusions of this article are included in the manuscript. The transcriptomic data and analysis files are openly available in figshare at https://figshare.com/s/8f53b7738153efa5feeb.

\section{Declarations}

Ethics approval and consent to participate

All experiments using mice were carried out according to an Animal Use Protocol approved by the Institutional Animal Care and Use Committee at University of Nebraska Medical Center.

\section{Consent for publication}

All authors have approved the manuscript and agree with its submission.

\section{Competing interests}

J.M., P.Y., B.D.K., C.B.G., R.L.M., and H.E.G. are named inventors on provisional patent entitled "Cells therapy for Alzheimer's disease" which is based upon the A $\beta$-targeting T cells developed in the present study (EFS ID: 42475225, Application number: 63175747, Docket number: 21084P). H.E.G is a member of the scientific advisory board at Longevity Biotech and a co-founder of Exavir Therapeutics, Inc. All other authors declare no conflict of interest.

\section{Author details}

${ }^{1}$ Department of Pharmacology and Experimental Neuroscience, University of Nebraska Medical Center, Omaha, NE 68198, USA. ²Department of Biological Sciences, Northern Kentucky University, Highland Heights, KY 41099, USA. ${ }^{3}$ University College London School of Pharmacy, Bloomsbury, London WC1E 6DE, UK. ${ }^{4}$ Department of Pathology and Microbiology, University of Nebraska Medical Center, Omaha, NE 68198, USA. ${ }^{5}$ Department of Pharmaceutical Sciences, University of Nebraska Medical Center, Omaha, NE 68198, USA. ${ }^{6}$ Therapeutic Chemistry Department, National Research Centre, Giza, Egypt. ${ }^{7}$ Mouse Genome Engineering Core Facility, University of Nebraska Medical Center, Omaha, NE, USA. ${ }^{8}$ Department of Safety Assessment, Genentech Inc., South San Francisco, CA 94080, USA. ${ }^{\circ}$ Department of Radiology, University of Nebraska Medical Center, Omaha, NE 68198, USA.

Received: 2 July 2021 Accepted: 28 October 2021

Published online: 19 November 2021

\section{References}

1. 2019 Alzheimer's disease facts and figures. Alzheimer's Dementia. 2019:15:321-87.

2. Machhi J, Kevadiya BD, Muhammad IK, Herskovitz J, Olson KE, Mosley RL, Gendelman HE. Harnessing regulatory T cell neuroprotective activities for treatment of neurodegenerative disorders. Mol Neurodegener. 2020;15:32

3. Machhi J, Prajapati N, Tripathi A, Parikh ZS, Kanhed AM, Patel K, Pillai PP, Giridhar R, Yadav MR. Synthesis and biological evaluation of novel multi-target-directed benzazepines against excitotoxicity. Mol Neurobiol. 2017;54:6697-722.

4. Machhi J, Sinha A, Patel P, Kanhed AM, Upadhyay P, Tripathi A, Parikh ZS, Chruvattil R, Pillai PP, Gupta S, et al. Neuroprotective potential of novel multi-targeted isoalloxazine derivatives in rodent models of Alzheimer's disease through activation of canonical Wnt/beta-catenin signalling pathway. Neurotox Res. 2016;29:495-513.

5. Schwab AD, Thurston MJ, Machhi J, Olson KE, Namminga KL, Gendelman HE, Mosley RL. Immunotherapy for Parkinson's disease. Neurobiol Dis. 2020;137:104760.

6. Kiyota T, Machhi J, Lu Y, Dyavarshetty B, Nemati M, Yokoyama I, Mosley RL, Gendelman HE. Granulocyte-macrophage colony-stimulating factor neuroprotective activities in Alzheimer's disease mice. J Neuroimmunol. 2018:319:80-92.

7. Marsh SE, Abud EM, Lakatos A, Karimzadeh A, Yeung ST, Davtyan H, Fote GM, Lau L, Weinger JG, Lane TE, et al. The adaptive immune system restrains Alzheimer's disease pathogenesis by modulating microglial function. Proc Natl Acad Sci USA. 2016;113:E1316-1325.

8. Hansen DV, Hanson JE, Sheng M. Microglia in Alzheimer's disease. J Cell Biol. 2018;217:459-72.

9. Kiyota T, Machhi J, Lu Y, Dyavarshetty B, Nemati M, Zhang G, Mosley RL, Gelbard HA, Gendelman HE. URMC-099 facilitates amyloid-beta clearance in a murine model of Alzheimer's disease. J Neuroinflamm. 2018;15:137.

10. Alberts B, Johnson A, Lewis J, Raff M, Roberts K, Walter P. Helper T cells and lymphocyte activation. In: Alberts B, Johnson A, Lewis J, Raff M, Roberts K, Walter P, editors. Molecular biology of the cell. 4th ed. New York: Garland Science; 2002.

11. Anderson KM, Olson KE, Estes KA, Flanagan K, Gendelman HE, Mosley RL. Dual destructive and protective roles of adaptive immunity in neurodegenerative disorders. Transl Neurodegener. 2014;3:25.

12. Mosley RL, Gendelman HE. T cells and Parkinson's disease. Lancet Neurol. 2017;16:769-71. 
13. Gate D, Saligrama N, Leventhal O, Yang AC, Unger MS, Middeldorp J, Chen K, Lehallier B, Channappa D, De Los Santos MB, et al. Clonally expanded CD8 T cells patrol the cerebrospinal fluid in Alzheimer's disease. Nature. 2020;577:399-404.

14. Saresella M, Calabrese E, Marventano I, Piancone F, Gatti A, Alberoni M, Nemni R, Clerici M. Increased activity of Th-17 and Th-9 lymphocytes and a skewing of the post-thymic differentiation pathway are seen in Alzheimer's disease. Brain Behav Immun. 2011;25:539-47.

15. Oberstein TJ, Taha L, Spitzer P, Hellstern J, Herrmann M, Kornhuber J, Maler JM. Imbalance of circulating Th17 and regulatory T cells in Alzheimer's disease: a case control study. Front Immunol. 2018;9:1213.

16. Larbi A, Pawelec G, Witkowski JM, Schipper HM, Derhovanessian E, Goldeck D, Fulop T. Dramatic shifts in circulating CD4 but not CD8 T cell subsets in mild Alzheimer's disease. J Alzheimers Dis. 2009;17:91-103.

17. McQuillan K, Lynch MA, Mills KH. Activation of mixed glia by Abetaspecific Th1 and Th17 cells and its regulation by Th2 cells. Brain Behav Immun. 2010;24:598-607.

18. Browne TC, McQuillan K, McManus RM, O'Reilly JA, Mills KH, Lynch MA IFN-gamma Production by amyloid beta-specific Th1 cells promotes microglial activation and increases plaque burden in a mouse model of Alzheimer's disease. J Immunol. 2013;190:2241-51.

19. Mittal K, Eremenko E, Berner O, Elyahu Y, Strominger I, Apelblat D, Nemirovsky A, Spiegel I, Monsonego A. CD4 T cells induce a subset of $\mathrm{MHCll}$-expressing microglia that attenuates alzheimer pathology. iScience. 2019;16:298-311.

20. Fisher Y, Strominger I, Biton S, Nemirovsky A, Baron R, Monsonego A. Th polarization of T cells injected into the cerebrospinal fluid induces brain immunosurveillance. J Immunol. 2014;192:92-102.

21. Schrum S, Probst P, Fleischer B, Zipfel PF. Synthesis of the CC-chemokines MIP-1alpha, MIP-1beta, and RANTES is associated with a type 1 immune response. J Immunol. 1996;157:3598-604.

22. Michielin O, Luescher I, Karplus M. Modeling of the TCR-MHC-peptide complex. J Mol Biol. 2000;300:1205-35.

23. Singh V, Bhoir S, Chikhale RV, Hussain J, Dwyer D, Bryce RA, Kirubakaran S, De Benedetti A. Generation of phenothiazine with potent anti-TLK1 activity for prostate cancer therapy. iScience. 2020;23:101474.

24. Mosconi L, Andrews RD, Matthews DC. Comparing brain amyloid deposition, glucose metabolism, and atrophy in mild cognitive impairment with and without a family history of dementia. J Alzheimers Dis. 2013;35:509-24

25. Niccoli T, Cabecinha M, Tillmann A, Kerr F, Wong CT, Cardenes D, Vincent AJ, Bettedi L, Li L, Gronke S, et al. Increased glucose transport into neurons rescues abeta toxicity in drosophila. Curr Biol. 2016;26:2291-300.

26. Chetelat G, Arbizu J, Barthel H, Garibotto V, Law I, Morbelli S, van de Giessen E, Agosta F, Barkhof F, Brooks DJ, et al. Amyloid-PET and (18) F-FDG-PET in the diagnostic investigation of Alzheimer's disease and other dementias. Lancet Neurol. 2020;19:951-62.

27. Gordon BA, Blazey TM, Su Y, Hari-Raj A, Dincer A, Flores S, Christensen J, McDade E, Wang G, Xiong C, et al. Spatial patterns of neuroimaging biomarker change in individuals from families with autosomal dominant Alzheimer's disease: a longitudinal study. Lancet Neurol. 2018;17:241-50.

28. Nordberg A, Rinne JO, Kadir A, Langstrom B. The use of PET in Alzheimer disease. Nat Rev Neurol. 2010;6:78-87.

29. Bouter C, Bouter Y. (18)F-FDG-PET in mouse models of Alzheimer's disease. Front Med (Lausanne). 2019;6:71.

30. Tolomeo D, Micotti E, Serra SC, Chappell M, Snellman A, Forloni G. Chemical exchange saturation transfer MRI shows low cerebral 2-deoxy-Dglucose uptake in a model of Alzheimer's Disease. Sci Rep. 2018;8:9576.

31. Nasrallah FA, Pages G, Kuchel PW, Golay X, Chuang KH. Imaging brain deoxyglucose uptake and metabolism by glucoCEST MRI. J Cereb Blood Flow Metab. 2013;33:1270-8.

32. Cunningham $C$, Hennessy E. Co-morbidity and systemic inflammation as drivers of cognitive decline: new experimental models adopting a broader paradigm in dementia research. Alzheimers Res Ther. 2015;7:33.

33. Walker KA, Hoogeveen RC, Folsom AR, Ballantyne CM, Knopman DS, Windham BG, Jack CR Jr, Gottesman RF. Midlife systemic inflammatory markers are associated with late-life brain volume: the ARIC study. Neurology. 2017;89:2262-70

34. Reynolds AD, Stone DK, Hutter JA, Benner EJ, Mosley RL, Gendelman HE. Regulatory T cells attenuate Th17 cell-mediated nigrostriatal dopaminergic neurodegeneration in a model of Parkinson's disease. J Immunol. 2010;184:2261-71.

35. Gendelman HE, Zhang Y, Santamaria P, Olson KE, Schutt CR, Bhatti D, Shetty BLD, Lu Y, Estes KA, Standaert DG, et al. Evaluation of the safety and immunomodulatory effects of sargramostim in a randomized, double-blind phase 1 clinical Parkinson's disease trial. NPJ Parkinsons Dis. 2017;3:10

36. Sakaguchi S. Naturally arising CD4+ regulatory t cells for immunologic self-tolerance and negative control of immune responses. Annu Rev Immunol. 2004;22:531-62.

37. Hori S, Nomura T, Sakaguchi S. Control of regulatory T cell development by the transcription factor Foxp3. Science. 2003;299:1057-61.

38. Viglietta $\vee$, Baecher-Allan C, Weiner HL, Hafler DA. Loss of functional suppression by CD4+CD25+ regulatory T cells in patients with multiple sclerosis. J Exp Med. 2004;199:971-9.

39. Saunders JA, Estes KA, Kosloski LM, Allen HE, Dempsey KM, Torres-Russotto DR, Meza JL, Santamaria PM, Bertoni JM, Murman DL, et al. CD4+ regulatory and effector/memory $T$ cell subsets profile motor dysfunction in Parkinson's disease. J Neuroimmune Pharmacol. 2012;7:927-38.

40. Beers DR, Henkel JS, Zhao W, Wang J, Huang A, Wen S, Liao B, Appel SH. Endogenous regulatory $T$ lymphocytes ameliorate amyotrophic lateral sclerosis in mice and correlate with disease progression in patients with amyotrophic lateral sclerosis. Brain. 2011;134:1293-314.

41. Baruch K, Rosenzweig N, Kertser A, Deczkowska A, Sharif AM, Spinrad A, Tsitsou-Kampeli A, Sarel A, Cahalon L, Schwartz M. Breaking immune tolerance by targeting Foxp3(+) regulatory T cells mitigates Alzheimer's disease pathology. Nat Commun. 2015;6:7967.

42. Hayden MS, Ghosh S. Signaling to NF-kappaB. Genes Dev. 2004; 18:2195-224.

43. Maddur MS, Miossec P, Kaveri SV, Bayry J. Th17 cells: biology, pathogenesis of autoimmune and inflammatory diseases, and therapeutic strategies. Am J Pathol. 2012;181:8-18.

44. Yan P, Bero AW, Cirrito JR, Xiao Q, Hu X, Wang Y, Gonzales E, Holtzman DM, Lee JM. Characterizing the appearance and growth of amyloid plaques in APP/PS1 mice. J Neurosci. 2009;29:10706-14.

45. Kiyota T, Morrison CM, Tu G, Dyavarshetty B, Weir RA, Zhang G, Xiong $\mathrm{H}$, Gendelman HE. Presenilin-1 familial Alzheimer's disease mutation alters hippocampal neurogenesis and memory function in CCL2 null mice. Brain Behav Immun. 2015;49:311-21.

46. Deng W, Aimone JB, Gage FH. New neurons and new memories: how does adult hippocampal neurogenesis affect learning and memory? Nat Rev Neurosci. 2010;11:339-50.

47. Shi Q, Chowdhury S, Ma R, Le KX, Hong S, Caldarone BJ, Stevens B, Lemere CA. Complement C3 deficiency protects against neurodegeneration in aged plaque-rich APP/PS1 mice. Sci Transl Med. 2017:9:eaaf6295.

48. Nicoll JA, Wilkinson D, Holmes C, Steart P, Markham H, Weller RO. Neuropathology of human Alzheimer disease after immunization with amyloidbeta peptide: a case report. Nat Med. 2003;9:448-52.

49. Monsonego A, Imitola J, Petrovic S, Zota V, Nemirovsky A, Baron R, Fisher Y, Owens T, Weiner HL. Abeta-induced meningoencephalitis is IFNgamma-dependent and is associated with $T$ cell-dependent clearance of Abeta in a mouse model of Alzheimer's disease. Proc Natl Acad Sci USA. 2006;103:5048-53.

50. Lexberg MH, Taubner A, Albrecht I, Lepenies I, Richter A, Kamradt T, Radbruch A, Chang HD. IFN-gamma and IL-12 synergize to convert in vivo generated Th17 into Th1/Th17 cells. Eur J Immunol. 2010;40:3017-27.

51. Monsonego A, Zota V, Karni A, Krieger Jl, Bar-Or A, Bitan G, Budson AE, Sperling R, Selkoe DJ, Weiner HL. Increased T cell reactivity to amyloid beta protein in older humans and patients with Alzheimer disease. J Clin Invest. 2003;112:415-22.

52. Faridar A, Thome AD, Zhao W, Thonhoff JR, Beers DR, Pascual B, Masdeu JC Appel SH. Restoring regulatory T-cell dysfunction in Alzheimer's disease through ex vivo expansion. Brain Commun. 2020;2:fcaa112.

53. Iliff JJ, Wang M, Liao Y, Plogg BA, Peng W, Gundersen GA, Benveniste H, Vates GE, Deane R, Goldman SA, et al. A paravascular pathway facilitates CSF flow through the brain parenchyma and the clearance of interstitial solutes, including amyloid beta. Sci Transl Med. 2012;4:147ra111.

54. Weller RO, Djuanda E, Yow HY, Carare RO. Lymphatic drainage of the brain and the pathophysiology of neurological disease. Acta Neuropathol. 2009:117:1-14. 
55. Da Mesquita S, Louveau A, Vaccari A, Smirnov I, Cornelison RC, Kingsmore KM, Contarino C, Onengut-Gumuscu S, Farber E, Raper D, et al. Functional aspects of meningeal lymphatics in ageing and Alzheimer's disease. Nature. 2018;560:185-91.

56. Man SM, Ma YR, Shang DS, Zhao WD, Li B, Guo DW, Fang WG, Zhu L, Chen YH. Peripheral T cells overexpress MIP-1alpha to enhance its transendothelial migration in Alzheimer's disease. Neurobiol Aging. 2007;28:485-96.

57. Heneka MT, O'Banion MK, Terwel D, Kummer MP. Neuroinflammatory processes in Alzheimer's disease. J Neural Transm (Vienna). 2010;117:919-47.

58. Ciccocioppo F, Lanuti P, Pierdomenico L, Simeone P, Bologna G, Ercolino E, Buttari F, Fantozzi R, Thomas A, Onofrj M, et al. The characterization of regulatory T-cell profiles in Alzheimer's disease and multiple sclerosis. Sci Rep. 2019:9:8788.

59. Dansokho C, Ait Ahmed D, Aid S, Toly-Ndour C, Chaigneau T, Calle V, Cagnard N, Holzenberger M, Piaggio E, Aucouturier P, Dorothee G. Regulatory $T$ cells delay disease progression in Alzheimer-like pathology. Brain. 2016;139:1237-51.

60. Baek H, Ye M, Kang GH, Lee C, Lee G, Choi DB, Jung J, Kim H, Lee S, Kim JS, et al. Neuroprotective effects of CD4+CD25+Foxp3+ regulatory T cells in a 3xTg-AD Alzheimer's disease model. Oncotarget. 2016;7:69347-57.

61. Reynolds AD, Banerjee R, Liu J, Gendelman HE, Mosley RL. Neuroprotective activities of $C D 4+C D 25+$ regulatory $T$ cells in an animal model of Parkinson's disease. J Leukoc Biol. 2007:82:1083-94.

62. Olson KE, Kosloski-Bilek LM, Anderson KM, Diggs BJ, Clark BE, Gledhill JM $\mathrm{Jr}$, Shandler SJ, Mosley RL, Gendelman HE. Selective VIP receptor agonists facilitate immune transformation for dopaminergic neuroprotection in MPTP-intoxicated mice. J Neurosci. 2015;35:16463-78.

63. Thonhoff JR, Beers DR, Zhao W, Pleitez M, Simpson EP, Berry JD, Cudkowicz ME, Appel SH. Expanded autologous regulatory T-lymphocyte infusions in ALS: A phase I, first-in-human study. Neurol Neuroimmunol Neuroinflamm. 2018:5:e465.

64. Gendelman HE, Mosley RL. A perspective on roles played by innate and adaptive immunity in the pathobiology of neurodegenerative disorders. J Neuroimmune Pharmacol. 2015;10:645-50.

65. Bottcher C, Schlickeiser S, Sneeboer MAM, Kunkel D, Knop A, Paza E, Fidzinski P, Kraus L, Snijders GJL, Kahn RS, et al. Human microglia regional heterogeneity and phenotypes determined by multiplexed single-cell mass cytometry. Nat Neurosci. 2019;22:78-90.

66. Jordao MJC, Sankowski R, Brendecke SM, Sagar, Locatelli G, Tai YH, Tay TL, Schramm E, Armbruster S, Hagemeyer N, et al. Single-cell profiling identifies myeloid cell subsets with distinct fates during neuroinflammation. Science. 2019;363:eaat7554.

67. Stratoulias V, Venero JL, Tremblay ME, Joseph B. Microglial subtypes: diversity within the microglial community. EMBO J. 2019;38:e101997.

68. Ransohoff RM. A polarizing question: do M1 and M2 microglia exist? Nat Neurosci. 2016;19:987-91.

69. Brew BJ, Pemberton L, Blennow K, Wallin A, Hagberg L. CSF amyloid beta42 and tau levels correlate with AIDS dementia complex. Neurology. 2005;65:1490-2.

70. Hu X, Leak RK, Thomson AW, YU F, Xia Y, Wechsler LR, Chen J. Promises and limitations of immune cell-based therapies in neurological disorders. Nat Rev Neurol. 2018;14:559-68.

71. Kiyota T, Gendelman HE, Weir RA, Higgins EE, Zhang G, Jain M. CCL2 affects beta-amyloidosis and progressive neurocognitive dysfunction in a mouse model of Alzheimer's disease. Neurobiol Aging. 2013;34:1060-8.

72. Mosley RL, Lu Y, Olson KE, Machhi J, Yan W, Namminga KL, Smith JR, Shandler SJ, Gendelman HE. A synthetic agonist to vasoactive intestinal peptide receptor-2 induces regulatory T cell neuroprotective activities in models of Parkinson's disease. Front Cell Neurosci. 2019;13:421.

73. Zhu K, Day T, Warshaviak D, Murrett C, Friesner R, Pearlman D. Antibody structure determination using a combination of homology modeling, energy-based refinement, and loop prediction. Proteins. 2014;82:1646-55.

74. Studer G, Tauriello G, Bienert S, Biasini M, Johner N, Schwede T. ProMod3-A versatile homology modelling toolbox. PLoS Comput Biol. 2021;17:e1008667.
75. Bienert S, Waterhouse A, de Beer TA, Tauriello G, Studer G, Bordoli L, Schwede T. The SWISS-MODEL Repository-new features and functionality. Nucleic Acids Res. 2017:45:D313-9.

76. Benkert P, Biasini M, Schwede T. Toward the estimation of the absolute quality of individual protein structure models. Bioinformatics. 2011;27:343-50.

77. Lee TS, Cerutti DS, Mermelstein D, Lin C, LeGrand S, Giese TJ, Roitberg A, Case DA, Walker RC, York DM. GPU-accelerated molecular dynamics and free energy methods in Amber18: performance enhancements and new features. J Chem Inf Model. 2018;58:2043-50.

78. Case D, Ben-Shalom I, Brozell S, Cerutti D, Cheatham T III, Cruzeiro V, Darden T, Duke R, Ghoreishi D, Gilson M, Gohlke H. AMBER 18. San Francisco: University of California; 2018.

79. Price DJ, Brooks CL 3rd. A modified TIP3P water potential for simulation with Ewald summation. J Chem Phys. 2004;121:10096-103.

80. Maier JA, Martinez C, Kasavajhala K, Wickstrom L, Hauser KE, Simmerling C. ff14SB: improving the accuracy of protein side chain and backbone parameters from ff99SB. J Chem Theory Comput. 2015;11:3696-713.

81. Peramo A. Solvated and generalised Born calculations differences using GPU CUDA and multi-CPU simulations of an antifreeze protein with AMBER. Mol Simul. 2016:42:1263-73.

82. Andersen HC. Rattle: a "velocity" version of the shake algorithm for molecular dynamics calculations. J Comput Phys. 1983;52:24-34.

83. Essmann U, Perera L, Berkowitz ML, Darden T, Lee H, Pedersen LG. A smooth particle mesh Ewald method. J Chem Phys. 1995;103:8577-93.

84. Roe DR, Cheatham TE 3rd. PTRAJ and CPPTRAJ: software for processing and analysis of molecular dynamics trajectory data. J Chem Theory Comput. 2013;9:3084-95.

85. Hsiao K, Chapman P, Nilsen S, Eckman C, Harigaya Y, Younkin S, Yang F, Cole G. Correlative memory deficits, Abeta elevation, and amyloid plaques in transgenic mice. Science. 1996;274:99-102.

86. Duff K, Eckman C, Zehr C, Yu X, Prada CM, Perez-tur J, Hutton M, Buee L, Harigaya $Y$, Yager D, et al. Increased amyloid-beta42(43) in brains of mice expressing mutant presenilin 1. Nature. 1996;383:710-3.

87. Kiyota T, Ingraham KL, Jacobsen MT, Xiong H, Ikezu T. FGF2 gene transfer restores hippocampal functions in mouse models of Alzheimer's disease and has therapeutic implications for neurocognitive disorders. Proc Natl Acad Sci USA. 2011;108:E1339-1348.

88. Kiyota T, Okuyama S, Swan RJ, Jacobsen MT, Gendelman HE, Ikezu T. CNS expression of anti-inflammatory cytokine interleukin-4 attenuates Alzheimer's disease-like pathogenesis in APP+PS1 bigenic mice. FASEB J. 2010;24:3093-102.

89. Kim M, Gillen J, Landman BA, Zhou J, van Zijl PC. Water saturation shift referencing (WASSR) for chemical exchange saturation transfer (CEST) experiments. Magn Reson Med. 2009;61:1441-50.

90. Subramanian A, Tamayo P, Mootha VK, Mukherjee S, Ebert BL, Gillette MA, Paulovich A, Pomeroy SL, Golub TR, Lander ES, Mesirov JP. Gene set enrichment analysis: a knowledge-based approach for interpreting genome-wide expression profiles. Proc Natl Acad Sci USA. 2005;102:15545-50.

91. da Huang W, Sherman BT, Lempicki RA. Systematic and integrative analysis of large gene lists using DAVID bioinformatics resources. Nat Protoc. 2009;4:44-57.

92. Wu G, Dawson E, Duong A, Haw R, Stein L. ReactomeFIViz: a Cytoscape app for pathway and network-based data analysis. F1000Res. 2014;3:146

93. Kanehisa M, Goto S. KEGG: kyoto encyclopedia of genes and genomes. Nucleic Acids Res. 2000;28:27-30.

94. Szklarczyk D, Gable AL, Lyon D, Junge A, Wyder S, Huerta-Cepas J, Simonovic M, Doncheva NT, Morris JH, Bork P, et al. STRING v11: protein-protein association networks with increased coverage, supporting functional discovery in genome-wide experimental datasets. Nucleic Acids Res. 2019;47:D607-13.

\section{Publisher's Note}

Springer Nature remains neutral with regard to jurisdictional claims in published maps and institutional affiliations. 